\title{
A moderate increase in ambient temperature modulates the Atlantic cod (Gadus morhua) spleen transcriptome response to intraperitoneal viral mimic injection
}

\author{
Tiago S Hori , A Kurt Gamperl, Marije Booman, Gordon W Nash and Matthew L Rise
}

\begin{abstract}
Background: Atlantic cod (Gadus morhua) reared in sea-cages can experience large variations in temperature, and these have been shown to affect their immune function. We used the new 20K Atlantic cod microarray to investigate how a water temperature change which, simulates that seen in Newfoundland during the springsummer (i.e. from $10^{\circ} \mathrm{C}$ to $16^{\circ} \mathrm{C}, 1^{\circ} \mathrm{C}$ increase every 5 days) impacted the cod spleen transcriptome response to the intraperitoneal injection of a viral mimic (polyriboinosinic polyribocytidylic acid, plC).

Results: The temperature regime alone did not cause any significant increases in plasma cortisol levels and only minor changes in spleen gene transcription. However, it had a considerable impact on the fish spleen transcriptome response to plC [290 and 339 significantly differentially expressed genes between $16^{\circ} \mathrm{C}$ and $10^{\circ} \mathrm{C}$ at 6 and 24 hours post-injection (HPI), respectively]. Seventeen microarray-identified transcripts were selected for QPCR validation based on immune-relevant functional annotations. Fifteen of these transcripts (i.e. 88\%), including DHX58, STAT1, IRF7, ISG15, RSAD2 and IKBa, were shown by QPCR to be significantly induced by plC.

Conclusions: The temperature increase appeared to accelerate the spleen immune transcriptome response to pIC. We found 41 and 999 genes differentially expressed between fish injected with PBS vs. plC at $10^{\circ} \mathrm{C}$ and sampled at $6 \mathrm{HPI}$ and $24 \mathrm{HPI}$, respectively. In contrast, there were 656 and 246 genes differentially expressed between fish injected with PBS vs. plC at $16^{\circ} \mathrm{C}$ and sampled at $6 \mathrm{HPI}$ and $24 \mathrm{HPI}$, respectively. Our results indicate that the modulation of mRNA expression of genes belonging to the NF-KB and type I interferon signal transduction pathways may play a role in controlling temperature-induced changes in the spleen's transcript expression response to plC. Moreover, interferon effector genes such as ISG15 and RSAD2 were differentially expressed between fish injected with $\mathrm{plC}$ at $10^{\circ} \mathrm{C}$ vs. $16^{\circ} \mathrm{C}$ at $6 \mathrm{HPI}$. These results substantially increase our understanding of the genes and molecular pathways involved in the negative impacts of elevated ambient temperature on fish health, and may also be valuable to our understanding of how accelerated global climate change could impact cold-water marine finfish species.
\end{abstract}

\footnotetext{
* Correspondence: tshori@mun.ca

Ocean Sciences Centre, Memorial University of Newfoundland, St. John's A1C

5S7, NL, Canada
} 


\section{Background}

The Atlantic cod (Gadus morhua) is an important commercial species in several countries including Canada, USA and Norway, whose supply has been threatened by declining wild stocks [1-3]. In recent years, the aquaculture of cod has emerged as a potential alternative source of fish for these markets $[4,5]$. Unfortunately, the development of Atlantic cod aquaculture still faces many challenges, including our incomplete understanding of how changes in the environment (e.g. seawater temperature) impact gadoid culture [2,6,7].

Atlantic cod reared in sea-cages are confined within a limited space, and therefore, are more likely than wild cod to be subjected to seasonal fluctuations in temperature. For example, high levels of mortality in farmed cod have been observed when temperatures increase during the summer months $[8,9]$. The temperatures to which farmed cod are often exposed in the summer months (e.g. $16^{\circ} \mathrm{C}$ to $20^{\circ} \mathrm{C}$ [8]) in themselves, however, are unlikely to be lethal for this species. In fact, previous work from our research group indicates that Atlantic cod juveniles can survive an incremental temperature increase of $1^{\circ} \mathrm{C}$ every 5 days until temperatures reach $\sim 22^{\circ} \mathrm{C}$ (Gamperl et al., unpublished data).

Elevated temperatures have been shown to modulate the immune response of several commercially important fish species such as the rainbow trout (Oncorhynchus mykiss) [10-13], sea bass (Dicentrarchus labrax) [14], orange-spotted grouper (Epinephelus coioides) [15], Atlantic salmon (Salmo salar) [16] and Atlantic cod $[9,17]$. However, the influence of temperature on fish immune function is variable. For example, while constant elevated temperatures can enhance the immune response of salmonids (e.g. improve the protection conferred by vaccines [12]), variable temperatures (i.e. daily fluctuations in temperature) can be immune suppressive in sea bass [14]. Since the thermal regime to which cod are exposed during the spring-summer months in Newfoundland is characterized by a gradual increase in temperature (i.e. variable temperature) and temperatures do not tend to reach the cod's critical thermal maximum (CTM) [9], we hypothesized that a temperature-dependent modulation of the immune system, which could lead to increased susceptibility to pathogens, may be associated with the losses sometimes observed in cod sea-cages.

Microarrays have been widely used to study the immune-relevant gene expression responses of fish and fish cell lines to pathogens and pathogen-associated molecular patterns (PAMPs) (e.g. Rise et al. [18]; Milev-Milovanovic et al. [19]; Workenhe et al. [20]; Booman et al. [21]). In this study we used the 20,000 element (20K) oligonucleotide microarray platform (GEO accession \# GPL10532 [21]), which includes sequences from both suppression subtractive hybridization ( $\mathrm{SSH}$ ) and normalized libraries enriched for immune and heat-stress responsive transcripts [22-26] (as well as sequences from several other normalized libraries), and reverse transcription - quantitative polymerase chain reaction (QPCR), to investigate the effects of an increasing temperature regime (gradually from $10^{\circ} \mathrm{C}$ to $16^{\circ} \mathrm{C}$ - Figures 1 and 2) on the Atlantic cod spleen response to the intra-peritoneal (IP) injection of the viral mimic polyriboinosinic polyribocytidylic acid (pIC). A better understanding of how moderately increased ambient temperature affects the genes and pathways involved in the cod's anti-viral response may shed light on the potential mechanisms of temperature-induced immune suppression [14,17,27-29]. This knowledge will not only be important for the emerging Atlantic cod aquaculture industry, but may also be valuable to our understanding of how accelerated global climate change [30] may impact cold-water marine finfish species.

\section{Results}

\section{Plasma cortisol}

Plasma cortisol averaged $( \pm \mathrm{SE}) \quad 15.3 \pm 6.4$ and $18.2 \pm 6.3 \mathrm{ng} \mathrm{ml}^{-1}$ in the "control before temperature increase" (CBTI - fish that remained at $10^{\circ} \mathrm{C}$ throughout the experiment) and "heat-exposed before temperature increase" (HBTI - fish that remained at $10^{\circ} \mathrm{C}$ up to this sampling point and were subsequently exposed to a gradual increase in temperature) groups, respectively. Cortisol values were approximately two-fold higher $\sim 5$ weeks later (i.e. one week after temperature had reached $16^{\circ} \mathrm{C}$ in the heat-exposed tanks) in both sets of fish (Figure $1 \mathrm{C}$ ) with the "control before injection" (CBI) group showing average cortisol levels of $33.1 \pm 6.8 \mathrm{ng} \mathrm{ml}^{-1}$ and the "heatexposed before injection" (HBI) group showing average cortisol levels of $37.7 \pm 7.5 \mathrm{ng} \mathrm{ml}^{-1}$. However, there were no significant differences in cortisol levels between the groups at either time point, or within the groups between time points.

\section{Impact of non-lethal chronic temperature elevation on the spleen transcriptome}

The first analysis carried out using significance analysis of microarrays (SAM) assessed the impact of the temperature increase alone on the cod spleen transcriptome. This analysis was carried out to investigate whether changes in the spleen transcriptome caused by temperature alone could be indicative of immune suppression. We compared 6 individuals from the CBI group to 6 individuals from the HBI group using a modified $t$-test assuming unequal variances in the SAM algorithm [31] as implemented in the Bioconductor package siggenes. The gradual $6^{\circ} \mathrm{C}$ increase in temperature had a very minor impact on spleen mRNA expression. Only 6 probes (all up-regulated) were identified as differentially expressed (at $\mathrm{FDR}=1 \%$ ) between the $\mathrm{CBI}$ and the $\mathrm{HBI}$ groups (Figure 2 and Additional file 1: Table S1). 


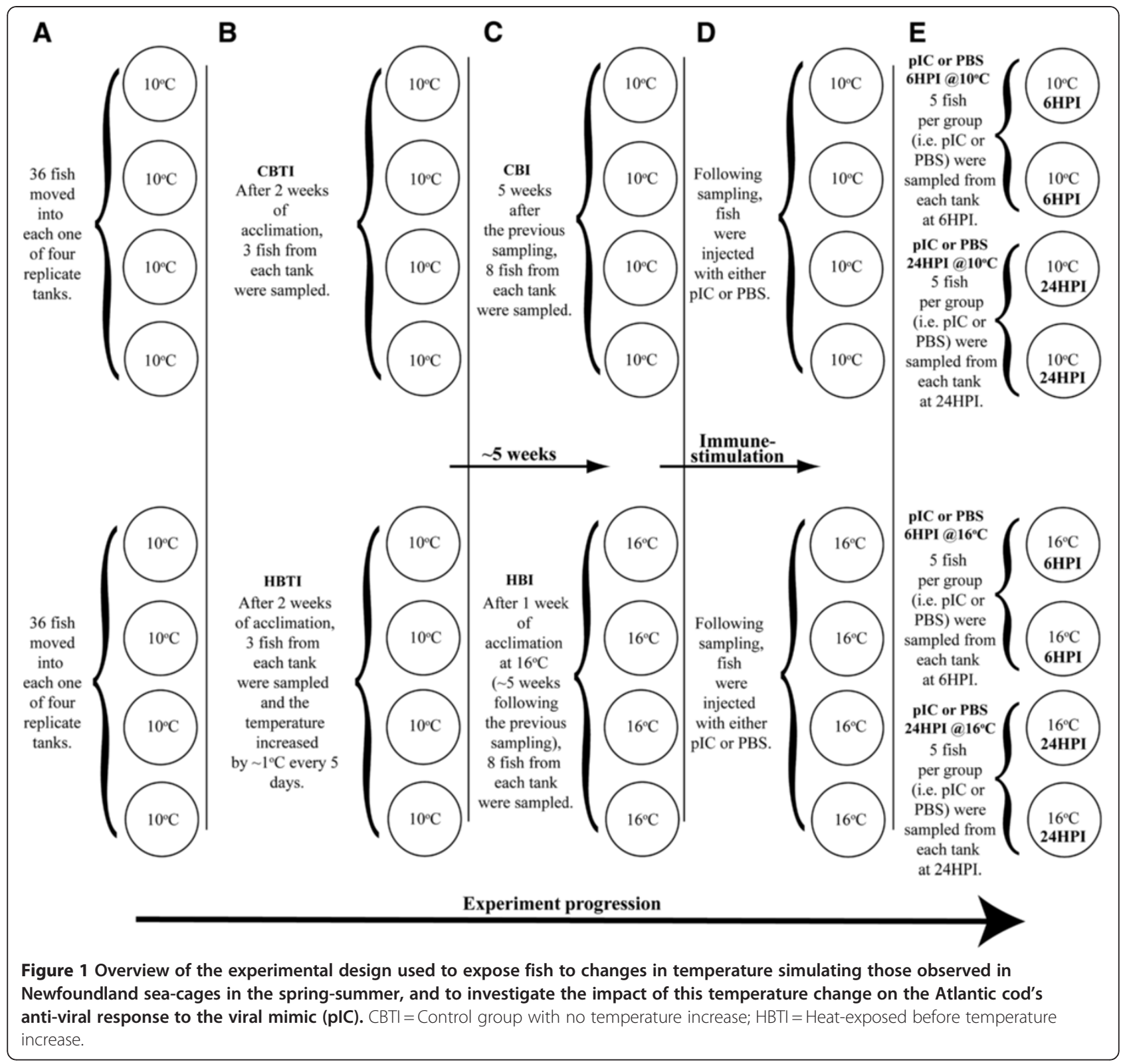

Impact of pIC injection on the spleen transcriptome

Polyriboinosinic polyribocytidylic acid (pIC) injected fish were also compared to their time- and temperaturematched phosphate buffered saline (PBS) injected controls using SAM. This gave us the following four comparisons: pIC 6HPI vs. PBS 6HPI (at 10 and $16^{\circ} \mathrm{C}$ ) and pIC 24HPI vs. PBS $24 \mathrm{HPI}$ (at $10^{\circ} \mathrm{C}$ and $16^{\circ} \mathrm{C}$ ). We identified 41 (36 up-regulated and 5 down-regulated) differentially expressed probes (at FDR $=1 \%$ ) between the pIC 6HPI vs. PBS $6 \mathrm{HPI}$ at $10^{\circ} \mathrm{C}$ (Figure 2; Table 1; Additional file 1: Table S2), 656 probes (617 upregulated and 39 down-regulated) between the pIC 6HPI vs. PBS $6 \mathrm{HPI}$ at $16^{\circ} \mathrm{C}$ (Figure 2; Table 1; Additional file 1: Table S3), 999 probes (851 up-regulated and 148 down-regulated) between pIC 24HPI vs. PBS 24HPI at $10^{\circ} \mathrm{C}$ (Figure 2; Table 2; Additional file 1: Table S4), and 246 probes (243 up-regulated and 3 down-regulated) between pIC 24HPI vs. PBS 24HPI at $16^{\circ} \mathrm{C}$ (Figure 2; Table 2; Additional file 1: Table S5). Selected probes having immune-related functional annotations are presented alongside overall fold-change values [i.e. experimental ratio of (ALEXA 647/ALEXA 555) / control ratio of (ALEXA 647/ALEXA 555)] in Tables 1 and 2. For complete information on microarray-identified informative probes, including raw p-values, d-values and standard deviations, please refer to Additional file 1: Tables S2-S5.

We also compared the PBS-injected fish to the temperature-matched pre-injected fish (i.e. CBI and $\mathrm{HBI}$ ) 


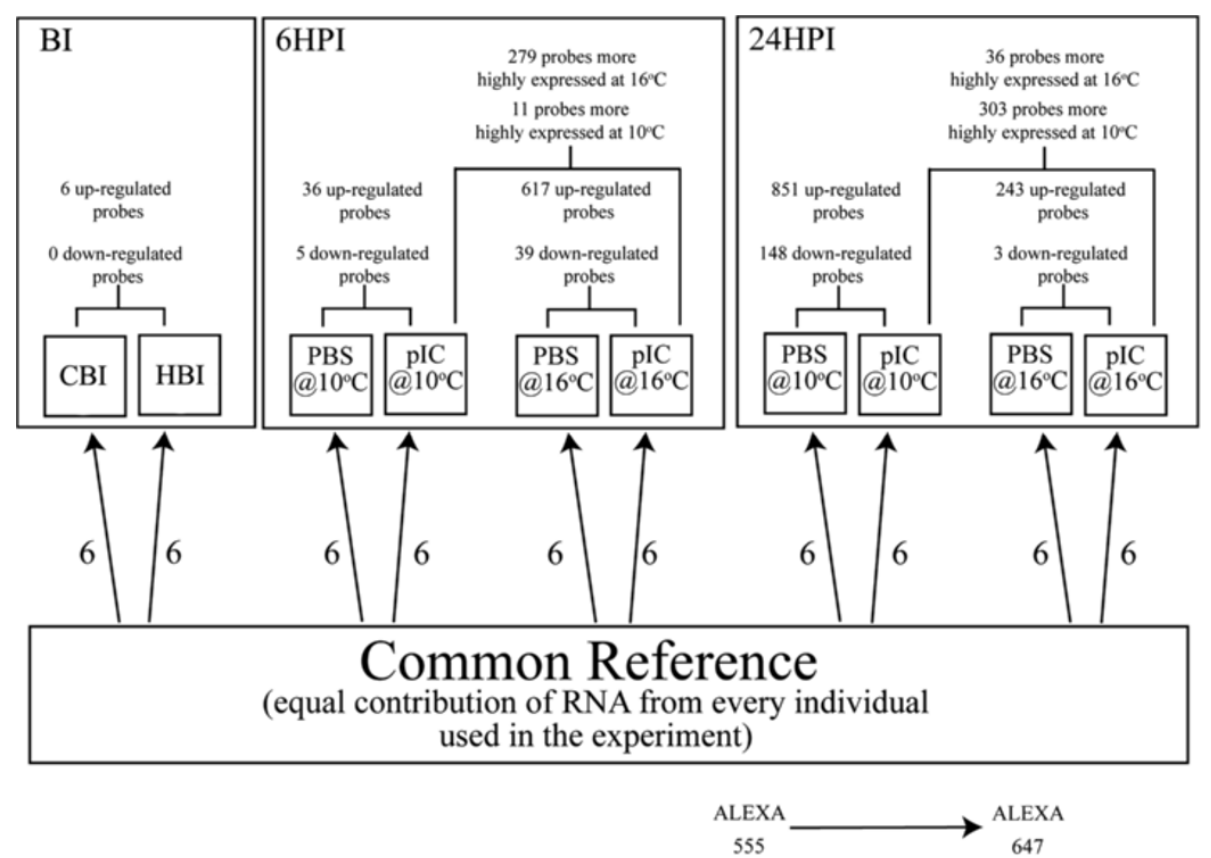

Figure 2 Oveview of the microarray experimental design and results. Each bracket connecting 2 boxes represents a direct comparison between these groups using SAM. All genes reported were found to have significant differential expression at FDR $=1 \%$.

to ensure that they were suitable controls. In this analysis, we found 29 probes differentially expressed (with $\mathrm{FDR}=1 \%$ ) between the PBS $6 \mathrm{HPI} @ 10^{\circ} \mathrm{C}$ and $\mathrm{CBI}$ groups, 40 differentially expressed probes between the PBS $6 \mathrm{HPI} @ 16^{\circ} \mathrm{C}$ and HBI groups, 18 differentially expressed probes between the PBS $24 \mathrm{HPI} @ 10^{\circ} \mathrm{C}$ and CBI groups, and 97 differentially expressed probes between the PBS $24 \mathrm{HPI} 16^{\circ} \mathrm{C}$ and HBI groups (for tables containing information on the above lists see Additional file 1: Table S6A-D). Given that only a small overlap (less than 5\%) was observed between the probes identified in these comparisons and the pIC vs. PBS comparisons (Additional file 1: Tables S6A-D), we concluded that the PBS groups were a suitable control for injection stress.

\section{Impact of increased temperature on pIC-induced mRNA expression}

In order to study the effect of the gradual temperature increase on the cod spleen transcript expression response to $\mathrm{pIC}$, we performed two direct comparisons: pIC 6HPI@16 $\mathrm{C}$ vs. pIC 6HPI@10 $\mathrm{C}$ and pIC $24 \mathrm{HPI} @ 16^{\circ} \mathrm{C}$ vs. pIC $24 \mathrm{HPI} 10^{\circ} \mathrm{C}$. This approach detected 290 differentially expressed probes (with FDR $=1 \%)$ (279 more highly expressed at $16^{\circ} \mathrm{C}$ and 11 more highly expressed at $10^{\circ} \mathrm{C}$ ) between pIC 6HPI@16 $6^{\circ}$ and pIC 6HPI@10 $\mathrm{C}$ (Table 1; Additional file 1: Table S7) and 339 differentially expressed probes (36 more highly expressed at $16^{\circ} \mathrm{C}$ and 303 more highly expressed at $10^{\circ} \mathrm{C}$ ) between pIC $24 \mathrm{HPI} @ 16^{\circ} \mathrm{C}$ and pIC 24HPI@10 $\mathrm{C}$ (Table 1; Additional file 1: Table S8). Selected microarray-identified probes having immune-related functional annotations are presented with fold-change values in Tables 1 and 2. For complete information on these probes, including raw $\mathrm{p}$ values, $\mathrm{d}$-values and standard deviations, please refer to Additional file 1: Tables S7 and S8.

We further analyzed these genes using gene ontology (GO) and hierarchical clustering analyses. Two distinct analyses were used to look at GO terms mapped to genes differentially expressed between fish injected with $\mathrm{pIC}$ at 10 and $16^{\circ} \mathrm{C}$. One analysis consisted of plotting level $2 \mathrm{GO}$ terms (belonging to the biological process branch) mapped to the genes differentially expressed between fish injected with $\mathrm{pIC}$ at 10 and $16^{\circ} \mathrm{C}$ (Figure 3). The second analysis consisted of using GOSSIP as implemented in Blast2GO to perform Fisher's exact test to check if any GO terms (belonging to any branch) were significantly $(\mathrm{p}<0.01)$ enriched in the genes responding to $\mathrm{pIC}$ (compared to $\mathrm{PBS}$ ) at 10 and $16^{\circ} \mathrm{C}$ for both time points. Figure 3 shows four pie charts depicting the proportions of level 2 biological process GO terms of: A) the 279 genes (Figure 2) more highly expressed in fish injected with pIC and sampled 6HPI at $16^{\circ} \mathrm{C}$ in comparison to the time-matched pIC injected fish at $10^{\circ} \mathrm{C}$; B) the 11 genes (Figure 2) more highly expressed in fish injected with $\mathrm{pIC}$ at $10^{\circ} \mathrm{C}$ and sampled $6 \mathrm{HPI}$ in comparison to the time-matched pIC injected fish at $16^{\circ} \mathrm{C}$; C) the 36 genes (Figure 2) more highly expressed in fish injected with $\mathrm{pIC}$ at $16^{\circ} \mathrm{C}$ and sampled 
Table 1 Selected probes ${ }^{1}$ representing immune-relevant genes that were differentially expressed between fish injected with PBS or pIC and sampled at 6 hours post-injection (6HPI) at 10 or $16^{\circ} \mathrm{C}$, or between fish injected with pIC but held at $10 \mathrm{vs} .16^{\circ} \mathrm{C}$ and sampled at $6 \mathrm{HPI}$

Probes identified as differentially expressed (FDR $=1 \%$ ) between PBS $6 \mathrm{HPI} @ 10^{\circ} \mathrm{C}$ and pIC $6 \mathrm{HPI} 10^{\circ} \mathrm{C}$, and between PBS6HPI@16 $16^{\circ}$ and pIC6HPI@ $16^{\circ} \mathrm{C}^{2}$

\begin{tabular}{|c|c|c|c|c|}
\hline Probe ID & Best BLASTx hit ${ }^{3}$ & $\begin{array}{l}\text { Fold-change } \\
\text { (pIC @ } 16^{\circ} \mathrm{C} / \\
\left.\text { PBS @ } 16^{\circ} \mathrm{C}\right)^{4}\end{array}$ & $\begin{array}{l}\text { Fold-change } \\
\text { (pIC @ } 10^{\circ} \mathrm{C} / \\
\left.\text { PBS @ } 10^{\circ} \mathrm{C}\right)^{4}\end{array}$ & $\begin{array}{l}\text { Fold-change } \\
\text { (pIC @ } 16^{\circ} \mathrm{C} / \\
\left.\text { pIC @ } 10^{\circ} \mathrm{C}\right)^{4}\end{array}$ \\
\hline 38613 & Interferon stimulated gene 15 [Gadus morhua] & 55.97 & 5.29 & 8.45 \\
\hline 38285 & DExD/H box RNA helicase [Paralichthys olivaceus] (Aliases: DHX58, LGP2) & 5.13 & 2.44 & 2.41 \\
\hline 45882 & $\begin{array}{l}\text { Retinoic acid receptor responder protein } 3 \text { [Osmerus mordax] } \\
\text { (Alias: HRAS-suppressor like 3) }\end{array}$ & 12.17 & 5.51 & - \\
\hline 38260 & Phosphoinositide phospholipase C-eta-2 [Homo sapiens] & 5.08 & 2.19 & 2.28 \\
\hline 44546 & Interferon regulatory factor 1 (IRF1) [Gadus mohua] & 4.74 & 1.88 & 2.48 \\
\hline 36426 & Cell division cycle 42 [Sus scrofa] & 4.00 & 2.16 & 1.85 \\
\hline 38042 & Deoxyribonuclease gamma precursor [Oncorhynchus mykiss] & 3.41 & 1.45 & 2.18 \\
\hline 41397 & Prostaglandin E synthase 3 [Osmerus mordax] & 2.86 & 1.87 & - \\
\hline 44530 & NF-kappa-B inhibitor alpha (IKBa) [Gadus morhua] & 2.15 & 3.12 & - \\
\hline 40721 & Nostrin protein [Danio rerio] & 2.12 & 2.04 & - \\
\hline 39371 & Novel immune-type receptor 4 [Oncorhynchus mykiss] & 2.03 & 1.52 & - \\
\hline 41181 & Ubiquitin carboxyl-terminal hydrolase 5 [Salmo salar] & 1.88 & 2.04 & - \\
\hline 36482 & CXC chemokine [Psetta maxima] & 1.74 & 1.71 & - \\
\hline
\end{tabular}

\begin{tabular}{|c|c|c|c|c|}
\hline Probe ID & Best BLASTx hit $^{3}$ & $\begin{array}{l}\text { Fold-change } \\
\text { (pIC @ } 16^{\circ} \mathrm{C} / \\
\left.\text { PBS @ } 16^{\circ} \mathrm{C}\right)^{4}\end{array}$ & $\begin{array}{l}\text { Fold-change } \\
\text { (pIC @ } 10^{\circ} \mathrm{C} / \\
\left.\text { PBS @ } 10^{\circ} \mathrm{C}\right)^{4}\end{array}$ & $\begin{array}{l}\text { Fold-change } \\
\left(\mathrm{plC} @ 16^{\circ} \mathrm{C}\right. \\
\left.\text { pIC @ } 10^{\circ} \mathrm{C}\right)^{4}\end{array}$ \\
\hline 46031 & Synaptic vesicle glycoprotein 2B [Harpegnathos saltator] & - & 3.35 & - \\
\hline 44581 & NF-kappa-B inhibitor alpha (IKBa) [Gadus morhua] & - & 1.46 & - \\
\hline 37564 & Heat shock protein 90 alpha [Paralichthys olivaceus] & - & -1.50 & - \\
\hline 49256 & Unknown & - & -10.59 & - \\
\hline
\end{tabular}

\begin{tabular}{|c|c|c|c|c|}
\hline Probe ID & Best BLASTx hit $^{3}$ & $\begin{array}{l}\text { Fold-change } \\
\text { (pIC @ } 16^{\circ} \mathrm{C} / \\
\left.\text { PBS @ } 16^{\circ} \mathrm{C}\right)^{4}\end{array}$ & $\begin{array}{l}\text { Fold-change } \\
\text { (plC @ } 10^{\circ} \mathrm{C} / \\
\left.\text { PBS @ } 10^{\circ} \mathrm{C}\right)^{4}\end{array}$ & $\begin{array}{l}\text { Fold-change } \\
\left(\text { pIC @ } 16^{\circ} \mathrm{C} /\right. \\
\left.\text { pIC @ } 10^{\circ} \mathrm{C}\right)^{4}\end{array}$ \\
\hline 44448 & $\begin{array}{l}\text { Small inducible cytokine SCYA104 [Paralabidochromis chilotes] } \\
\text { (Alias: gmSCYA123a ) }\end{array}$ & 24.34 & - & 7.29 \\
\hline 38356 & Sacsin [Homo sapiens] (Alias: SACS) & 12.54 & - & 11.14 \\
\hline 48390 & Endonuclease domain-containing 1 protein precursor [Salmo salar] & 9.94 & - & - \\
\hline 39328 & Zinc finger, NFX1-type containing 1 (ZNFX1) [Homo sapiens] & 9.05 & - & 2.67 \\
\hline 43196 & VHSV-induced protein [Oncorhynchus mykiss] & 8.03 & - & 3.35 \\
\hline 38639 & Interleukin-8 variant 5 (IL-8) [Ictalurus punctatus] & 7.60 & - & 5.88 \\
\hline 43201 & $\begin{array}{l}\text { Viperin [Niphon spinosus] (Aliases: Radical S-adenosyl methionine domain } \\
\text { containing protein 2, RSAD2) }\end{array}$ & 6.89 & - & 5.43 \\
\hline 50762 & Unknown & 6.70 & - & - \\
\hline 37299 & GADD45 alpha [Anoplopoma fimbria] & 2.27 & - & 3.19 \\
\hline 38617 & Interferon-inducible GTPase a [Salmo salar] & 6.53 & - & 2.80 \\
\hline 47384 & Unnamed protein product [Tetraodon nigroviridis] & 6.50 & - & 7.71 \\
\hline 36121 & Anti-apoptotic protein NR-13 [Gadus morhua] & 4.44 & - & - \\
\hline 37609 & Hepcidin precursor [Gadus morhua] & 4.30 & - & - \\
\hline 36384 & CC chemokine type 3 [Gadus morhua] & 3.55 & - & - \\
\hline
\end{tabular}


Table 1 Selected probes ${ }^{1}$ representing immune-relevant genes that were differentially expressed between fish injected with PBS or pIC and sampled at 6 hours post-injection $(6 \mathrm{HPI})$ at 10 or $16^{\circ} \mathrm{C}$, or between fish injected with pIC but held at 10 vs. $16^{\circ} \mathrm{C}$ and sampled at $6 \mathrm{HPI}$ (Continued)

\begin{tabular}{|c|c|c|c|c|}
\hline 44371 & Probable E3 ubiquitin-protein ligase RNF144A-A [Esox lucius] & 3.43 & - & - \\
\hline 36190 & Bloodthirsty [Gadus morhua] & 3.38 & - & 2.05 \\
\hline 37904 & Type 2 double stranded RNA activated protein kinase [Gadus morhua] (Alias: PKR) & 2.98 & - & 2.52 \\
\hline 44579 & Mitogen-activated protein kinase kinase 4 [Gadus morhua] & 2.76 & - & 1.90 \\
\hline 38599 & Interferon regulatory factor 10 (IRF10) [Paralichthys olivaceus] & 2.63 & - & - \\
\hline 38655 & Interferon regulatory factor 7 (IRF7) [Psetta maxima] & 2.49 & - & 2.15 \\
\hline 38788 & Mannose-specific lectin precursor [Esox lucius] & 2.39 & - & - \\
\hline 39119 & Ras homolog gene family, member T1a [Danio rerio] & 2.25 & - & 1.75 \\
\hline 38625 & Interleukin 12 receptor beta 2.b [Danio rerio] & 2.12 & - & - \\
\hline 36407 & CD9 antigen [Salmo salar] & 2.05 & - & 1.44 \\
\hline 44615 & Toll-like receptor 9 (TLR9) [Gadus morhua] & 2.03 & - & - \\
\hline 37854 & Interferon-inducible protein Gig2 [Siniperca chuatsi] & 2.01 & - & - \\
\hline 35877 & Alpha-2-macroglobulin [Epinephelus coioides] & 1.94 & - & - \\
\hline 41703 & Ras-related protein Rab-10 [Salmo salar] & 1.90 & - & - \\
\hline 36380 & CC chemokine type 2 [Gadus morhua] & 1.89 & - & - \\
\hline 36142 & Beta-2-microglobulin [Gadus morhua] & 1.73 & - & - \\
\hline 38629 & Interleukin-1 receptor-associated kinase 4 (IRAK4) [Gadus morhua] & 1.67 & - & - \\
\hline 38090 & GTPase IMAP family member 7 [Salmo salar] & 1.64 & - & - \\
\hline 36328 & FLICE-like inhibitory protein [Oryzias latipes] & 1.58 & - & 1.40 \\
\hline 45132 & DEAD (Asp-Glu-Ala-Asp) box polypeptide 10-like [Bos taurus] & 1.55 & - & - \\
\hline 44434 & Type 1 death domain-containing protein [Gadus morhua] & 1.48 & - & - \\
\hline 41613 & Dhx33 protein [Xenopus laevis] & 1.47 & - & - \\
\hline 37498 & GTP-binding nuclear protein Ran [Osmerus mordax] & 1.43 & - & 1.36 \\
\hline 36122 & Novel protein similar to BCL2-related ovarian killer [Danio rerio] & 1.43 & - & - \\
\hline 44431 & Caspase 10 [Gadus morhua] & 1.33 & - & 1.34 \\
\hline 37561 & Stress-70 protein, mitochondrial precursor [Salmo salar] (Alias: Mortalin) & 1.32 & - & - \\
\hline 44606 & Toll-like receptor 3 (TLR3) [Gadus morhua] & 1.32 & - & - \\
\hline
\end{tabular}

${ }^{1}$ Probes presented in this table were selected based on their known roles in vertebrate immune responses. Some genes without a BLASTx hit (e.g. Unknowns) were added because they presented a pIC-induced fold-change higher than 5, and therefore, could represent novel immune-relevant genes. For a complete list of microarray-identified informative probes please refer to Additional file 1: Tables S2-S5 and S7-S8.

${ }^{2}$ Fold-change in probe expression is also shown for pIC @ $16^{\circ} \mathrm{C}$ vs. pIC @ $10^{\circ} \mathrm{C}$ when significant differential expression was found in the PBS vs. pIC comparisons. ${ }^{3}$ Informative genes were re-annotated using the contig or EST from which the probe printed in the array was designed by comparing the referred sequence to the NCBI's nr database using the BLASTx algorithm as implemented by Blast2GO [67]. The best BLASTx hit (E-value cutoff of 10-5) with an informative name (i.e. not predicted, probable or unnamed protein) is presented in this table. Synonyms were obtained from SWISS-PROT, GENE CARDS and other BLASTx hits as long as they had E-value $<10^{-5}$, or from the literature ('Borza et al. [58]).

${ }^{4}$ Fold-changes are only reported when probes were differently expressed (FDR $=1 \%$ ) in a given comparison (e.g. pIC@10 ${ }^{\circ} \mathrm{C}$ vs. pIC@16 $6^{\circ} \mathrm{C}$ ) and are shown as outputted by siggenes; otherwise a dash (-) is presented in place of the fold-change. Fold-change values preceded by a minus ("-") sign represent overall fold down-regulation for a particular comparison. For standard deviation, $\mathrm{p}$ - and d-values, please refer to Additional file 1: Tables S2-S5 and S7-S8.

24HPI in comparison to the time-matched pIC injected fish at $10^{\circ} \mathrm{C}$; and $\mathrm{D}$ ) the 303 genes (Figure 2) more highly expressed in fish injected with $\mathrm{pIC}$ at $10^{\circ} \mathrm{C}$ and sampled 24HPI in comparison with the time-matched pIC injected fish at $16^{\circ} \mathrm{C}$.

Several biological processes were highly represented (i.e. by more than 10 sequences) in the 629 genes differentially expressed between fish stimulated with pIC at the different temperatures (i.e. identified in the direct comparisons between fish injected with pIC at 10 and $16^{\circ} \mathrm{C}$ and sampled at $6 \mathrm{HPI}$ and 24HPI). Among these were: cellular component organization, cellular process, developmental process, signaling, biological regulation, response to stimulus, immune system process, and death. Only 4 biological process level 2 GO terms were mapped to the 11 genes more highly expressed in fish stimulated with pIC at $10^{\circ} \mathrm{C}$ and sampled at $6 \mathrm{HPI}$ compared to those stimulated with $\mathrm{pIC}$ at $16^{\circ} \mathrm{C}$ and sampled 
Table 2 Selected probes ${ }^{1}$ representing immune-relevant genes that were differentially expressed between fish injected with PBS or pIC at 24 hour post-injection (24HPI) at 10 or $16^{\circ} \mathrm{C}$, or between fish injected with pIC but held at 10 vs.

$16^{\circ} \mathrm{C}$ and sampled at $24 \mathrm{HPI}$

Probes identified as differentially expressed (FDR = 1\%) between PBS $24 \mathrm{HPI} @ 10^{\circ} \mathrm{C}$ and pIC $24 \mathrm{HPI} 10^{\circ} \mathrm{C}$, and PBS $24 \mathrm{HPI} 16^{\circ} \mathrm{C}$ and pIC 24HPI@16 ${ }^{\circ} \mathrm{C}^{2}$

\begin{tabular}{|c|c|c|c|c|}
\hline Probe ID & Best BLASTx hit $^{3}$ & $\begin{array}{l}\text { Fold-change } \\
\text { (pIC @ } 16^{\circ} \mathrm{C} / \\
\left.\text { PBS @ } 16^{\circ} \mathrm{C}\right)^{4}\end{array}$ & $\begin{array}{l}\text { Fold-change } \\
\text { (pIC @ } 10^{\circ} \mathrm{C} / \\
\left.\text { PBS @ } 10^{\circ} \mathrm{C}\right)^{4}\end{array}$ & $\begin{array}{l}\text { Fold-change } \\
\text { (pIC @ } 16^{\circ} \mathrm{C} / \\
\left.\text { pIC @ } 10^{\circ} \mathrm{C}\right)^{4}\end{array}$ \\
\hline 38604 & Interferon stimulated gene 15 (ISG15) [Gadus morhua] & 38.35 & 90.24 & -3.05 \\
\hline 45882 & $\begin{array}{l}\text { Retinoic acid receptor responder protein } 3 \text { [Osmerus mordax] } \\
\text { (Alias: HRAS-suppressor like 3) }\end{array}$ & 31.10 & 27.01 & - \\
\hline 44590 & $\begin{array}{l}\text { RIG-I C-terminal domain-containing protein } 1 \text { [Gadus morhua] } \\
\text { (Aliases: DHX58, LGP2) }\end{array}$ & 12.13 & 30.48 & - \\
\hline 48390 & Endonuclease domain-containing 1 protein precursor [Salmo salar] & 11.53 & 14.24 & - \\
\hline 38356 & Sacsin [Homo sapiens] (Alias: SACS) & 9.88 & 17.37 & - \\
\hline 44448 & $\begin{array}{l}\text { Small inducible cytokine SCYA104 [Paralabidochromis chilotes] } \\
\text { (Alias: gmSCYA123ㄱ) }\end{array}$ & 7.28 & 66.64 & -2.34 \\
\hline 38638 & Interleukin-8 variant 5 (IL-8) [/ctalurus punctatus] & 6.92 & 25.33 & -5.66 \\
\hline 35718 & A disintegrin and metalloproteinase domain 8a [Danio rerio] & 6.12 & 3.02 & - \\
\hline 47329 & Unnamed protein product [Tetraodon nigroviridis] & 5.81 & 5.52 & - \\
\hline 41269 & Regulator of nonsense transcripts 1-like [Bos taurus] & 5.07 & 13.93 & -2.16 \\
\hline 44859 & Novel protein [Danio rerio] & 4.98 & 11.50 & -2.34 \\
\hline 37854 & Interferon-inducible protein Gig2 [Siniperca chuatsi] & 3.41 & 4.14 & - \\
\hline 44324 & Aminopeptidase N [Camponotus floridanus] & 3.04 & 3.45 & - \\
\hline 44472 & CC chemokine type 3 [Gadus morhua] & 2.75 & 1.75 & - \\
\hline 55231 & Unknown & 2.65 & 5.17 & - \\
\hline 47410 & Probable E3 ubiquitin-protein ligase RNF144A-A [Salmo salar] & 2.64 & 7.10 & -2.83 \\
\hline 47613 & Unnamed protein product [Tetraodon nigroviridis] & 2.48 & 5.22 & -2.72 \\
\hline 37542 & 10 kDa heat shock protein, mitochondrial [Esox lucius] & 2.45 & 1.61 & - \\
\hline 44919 & Novel protein similar to vertebrate IGSF3 [Danio rerio] & 2.43 & 3.12 & - \\
\hline 44371 & Probable E3 ubiquitin-protein ligase RNF144A-A [Esox lucius] & 2.35 & 4.56 & -1.92 \\
\hline 37299 & GADD45 alpha [Anoplopoma fimbria] & 2.25 & 4.52 & - \\
\hline 44598 & STAT1 [Gadus morhua] & 2.12 & 1.98 & - \\
\hline 36190 & Bloodthirsty [Gadus morhua] & 2.11 & 3.43 & -1.78 \\
\hline 36612 & Complement component C3 [Paralichthys olivaceus] & 2.07 & 2.47 & - \\
\hline 43196 & VHSV-induced protein [Oncorhynchus mykiss] & 2.02 & 4.04 & - \\
\hline 44546 & Interferon regulatory factor 1 (IRF1) [Gadus mohua] & 1.86 & 3.35 & -1.84 \\
\hline 37566 & Heat shock protein HSP 90-alpha [Salmo salar] & 1.80 & 1.34 & 1.55 \\
\hline 36407 & CD9 antigen [Salmo salar] & 1.78 & 1.93 & - \\
\hline 36426 & Cell division cycle 42 [Sus scrofa] & 1.66 & 1.93 & - \\
\hline 35957 & Apolipoprotein A-IV precursor [Salmo salar] & 1.60 & 2.58 & -1.53 \\
\hline 38545 & IgD heavy chain constant region variant b [Gadus morhua] & 1.60 & 1.43 & - \\
\hline 44865 & Hect domain and RLD 5 [Bos Taurus] & 1.52 & 1.94 & -1.40 \\
\hline 36923 & DnaJ-like subfamily A member 4 [Paralichthys olivaceus] & 1.51 & 1.43 & - \\
\hline
\end{tabular}

DnaJ-like subfamily A member 4 [Paralichthys olivaceus]

\begin{tabular}{|c|c|c|c|c|}
\hline Probe ID & Best BLASTx hit $^{3}$ & $\begin{array}{l}\text { Fold-change } \\
\text { (pIC @ } 16^{\circ} \mathrm{C} / \\
\left.\text { PBS @ } 16^{\circ} \mathrm{C}\right)^{4}\end{array}$ & $\begin{array}{l}\text { Fold-change } \\
\text { (pIC @ } 10^{\circ} \mathrm{C} / \\
\left.\text { PBS } @ 10^{\circ} \mathrm{C}\right)^{4}\end{array}$ & $\begin{array}{l}\text { Fold-change } \\
\text { (pIC @ } 16^{\circ} \mathrm{C} \\
\left.\text { pIC @ } 10^{\circ} \mathrm{C}\right)^{4}\end{array}$ \\
\hline 38617 & Interferon-inducible GTPase a [Salmo salar] & - & 8.88 & - \\
\hline 49247 & Unknown & - & 5.74 & -2.86 \\
\hline
\end{tabular}


Table 2 Selected probes ${ }^{1}$ representing immune-relevant genes that were differentially expressed between fish injected with PBS or pIC at 24 hour post-injection (24HPI) at 10 or $16^{\circ} \mathrm{C}$, or between fish injected with pIC but held at 10 vs. $16^{\circ} \mathrm{C}$ and sampled at $24 \mathrm{HPI}$ (Continued)

\begin{tabular}{|c|c|c|c|c|}
\hline 43201 & $\begin{array}{l}\text { Viperin [Niphon spinosus] (Aliases: Radical S-adenosyl methionine domain } \\
\text { containing protein 2, RSAD2) }\end{array}$ & - & 4.68 & -2.45 \\
\hline 38260 & Phospholipase C-eta-2 [Homo sapiens] & - & 4.11 & - \\
\hline 39368 & Novel immune type receptor protein [Danio rerio] & - & 3.23 & \\
\hline 40397 & Deltex-3-like [Salmo salar] & - & 2.76 & -2.18 \\
\hline 39119 & Ras homolog gene family, member T1a [Danio rerio] & - & 2.66 & - \\
\hline 44579 & Mitogen-activated protein kinase kinase 4 [Gadus morhua] & - & 2.61 & -1.66 \\
\hline 40174 & $60 \mathrm{kDa}$ heat shock protein, mitochondrial precursor [Salmo salar] & - & 2.46 & - \\
\hline 37609 & Hepcidin precursor [Gadus morhua] & - & 2.44 & - \\
\hline 36339 & Caspase-1 [Dicentrarchus labrax] & - & 2.42 & -1.78 \\
\hline 38788 & Mannose-specific lectin precursor [Esox lucius] & - & 2.30 & -1.80 \\
\hline 36364 & Cathepsin L precursor [Anoplopoma fimbria] & - & 2.11 & - \\
\hline 38599 & Interferon regulatory factor 10 (IRF10) [Paralichthys olivaceus] & & 2.05 & - \\
\hline 44503 & Type 2 double stranded RNA activated protein kinase [Gadus morhua] (Alias: PKR) & - & 1.93 & - \\
\hline 45146 & DNA (cytosine-5-)-methyltransferase 7 [Danio rerio] & & 1.89 & -1.79 \\
\hline 44434 & Type 1 death domain-containing protein [Gadus morhua] & - & 1.89 & - \\
\hline 36797 & Cytotoxic and regulatory $T$ cell protein [Oncorhynchus mykiss] & - & 1.87 & -1.81 \\
\hline 40721 & Nostrin protein [Danio rerio] & - & 1.86 & - \\
\hline 44839 & Disulfide-isomerase A3 precursor [Salmo salar] & - & 1.79 & - \\
\hline 44518 & Fas [Gadus morhua] & - & 1.74 & -1.77 \\
\hline 36121 & Anti-apoptotic protein NR-13 [Gadus morhua] & - & 1.67 & - \\
\hline 37498 & GTP-binding nuclear protein Ran [Osmerus mordax] & - & 1.64 & -1.54 \\
\hline 44550 & Interleukin-1 receptor-associated kinase 4 (IRAK4) [Gadus morhua] & - & 1.63 & -1.37 \\
\hline 36328 & FLICE-like inhibitory protein [Oryzias latipes] & - & 1.59 & - \\
\hline 38619 & Interferon-inducible protein Gig1 [Psetta maxima] & - & 1.55 & - \\
\hline 44615 & Toll-like receptor 9 (TLR9) [Gadus morhua] & - & 1.54 & - \\
\hline 42836 & Tumor necrosis factor receptor-2 [Paralichthys olivaceus] & - & 1.54 & - \\
\hline 42266 & Strawberry notch homologue 1 [Danio rerio] & - & 1.53 & - \\
\hline 35877 & Alpha-2-macroglobulin [Epinephelus coioides] & - & 1.52 & - \\
\hline 42501 & T-complex protein 1 subunit delta [Takifugu rubripes] & - & 1.46 & - \\
\hline 41397 & Prostaglandin E synthase 3 [Osmerus mordax] & - & 1.45 & -1.49 \\
\hline 36967 & E3 SUMO-protein ligase RanBP2 [Homo sapiens] & - & 1.42 & - \\
\hline 38108 & Inhibitor of nuclear factor kappa-B kinase subunit alpha [Danio rerio] (Alias: IKKa) & - & 1.41 & - \\
\hline 38631 & Interleukin-11a [Takifugu rubripes] & - & 1.40 & - \\
\hline 40138 & 78 kDa glucose-regulated protein precursor [Salmo salar] & - & 1.39 & - \\
\hline 37118 & Novel protein similar to vertebrate EIF4E [Danio rerio] & - & 1.35 & 1.31 \\
\hline 41690 & RAS guanyl-releasing protein 1 [Xenopus tropicalis] & - & 1.33 & - \\
\hline 37568 & Glucose-regulated protein 94 [Paralichthys olivaceus] & - & 1.33 & - \\
\hline 39371 & Novel immune-type receptor 4 [Oncorhynchus mykiss] & - & 1.31 & -1.33 \\
\hline 39063 & MHC class la antigen [Gadus morhua] & - & 1.28 & - \\
\hline 41711 & Rab8b protein [Xenopus tropicalis] & - & 1.27 & - \\
\hline 35876 & Alpha-2-macroglobulin receptor-associated protein [Homo sapiens] & - & 1.26 & - \\
\hline 41613 & Dhx33 protein [Xenopus laevis] & - & 1.24 & - \\
\hline 45113 & Methyltransferase-like protein 2 [Salmo salar] & - & -1.48 & 1.44 \\
\hline
\end{tabular}


Table 2 Selected probes ${ }^{1}$ representing immune-relevant genes that were differentially expressed between fish injected with PBS or pIC at 24 hour post-injection (24HPI) at 10 or $16^{\circ} \mathrm{C}$, or between fish injected with pIC but held at 10 vs. $16^{\circ} \mathrm{C}$ and sampled at $24 \mathrm{HPI}$ (Continued)

\begin{tabular}{|c|c|c|c|c|}
\hline 38713 & $\begin{array}{l}\text { KH domain-containing, RNA-binding, signal transduction-associated protein } 1 \\
\text { [Salmo salar] }\end{array}$ & - & -1.54 & - \\
\hline 41688 & Novel protein similar to vertebrate IQGAP2 [Danio rerio] & - & -1.65 & - \\
\hline 37695 & G1/S-specific cyclin-D1 [Salmo salar] & - & -1.68 & - \\
\hline 35934 & Annexin max3 [Oryzias latipes] & - & -1.83 & - \\
\hline 38596 & Interferon induced protein 2 [/ctalurus punctatus] & - & -2.38 & - \\
\hline \multicolumn{5}{|c|}{ Probes identified as differentially expressed (FDR 1\%) between pIC $24 \mathrm{HPI} @ 16^{\circ} \mathrm{C}$ and PBS $24 \mathrm{HPI} 116^{\circ} \mathrm{C}$ only ${ }^{2}$} \\
\hline Probe ID & Best BLASTx hit $^{3}$ & $\begin{array}{l}\text { Fold-change } \\
\text { (pIC @ } 16^{\circ} \mathrm{C} / \\
\left.\text { PBS @ } 16^{\circ} \mathrm{C}\right)^{4}\end{array}$ & $\begin{array}{l}\text { Fold-change } \\
\left(p I C @ 10^{\circ} \mathrm{C} /\right. \\
\left.\text { PBS @ } 10^{\circ} \mathrm{C}\right)^{4}\end{array}$ & $\begin{array}{l}\text { Fold-change } \\
\text { (pIC @ } 16^{\circ} \mathrm{C} / \\
\left.\text { pIC @ } 10^{\circ} \mathrm{C}\right)^{4}\end{array}$ \\
\hline 44465 & CC chemokine type 2 [Gadus morhua] & 3.76 & - & - \\
\hline 37456 & Goose-type lysozyme 2 [Gadus morhua] & 3.36 & - & - \\
\hline 36381 & CC chemokine type 2 [Gadus morhua] & 2.98 & - & - \\
\hline 42545 & Thioredoxin [Oncorhynchus mykiss] & 2.35 & - & 2.17 \\
\hline 36388 & CEBPA protein [Bos taurus] & 1.86 & - & - \\
\hline 36468 & CCT epsilon subunit [Carassius auratus] (Alias: CCT5) & 1.66 & - & 1.49 \\
\hline 38014 & Ctssa protein [Danio rerio] & 1.66 & - & - \\
\hline 35923 & Annexin A4 [Ctenopharyngodon idella] & 1.62 & - & - \\
\hline 42502 & Tcp1 protein [Danio rerio] (Alias: CCT1) & 1.56 & - & - \\
\hline 36813 & DEAD (Asp-Glu-Ala-Asp) box polypeptide 23 [Xenopus tropicalis] & 1.55 & - & - \\
\hline 40508 & Glutathione S-transferase Mu 3 [Anoplopoma fimbria] & 1.53 & - & 1.61 \\
\hline 45010 & Heat shock protein 90 alpha [Paralichthys olivaceus] & 1.52 & - & 1.66 \\
\hline 37573 & Heat shock protein 90 alpha [Paralichthys olivaceus] & 1.42 & - & 1.65 \\
\hline 43222 & Warm temperature acclimation protein 65-1 [Dicentrarchus labrax] & 1.42 & - & - \\
\hline 37574 & Heat shock protein 90 beta [Paralichthys olivaceus] & 1.37 & - & 1.52 \\
\hline 39904 & Peptidylprolyl isomerase A (cyclophilin A) [Danio rerio] & 1.33 & - & - \\
\hline \multicolumn{5}{|c|}{ Probes identified as differentially expressed (FDR = 1\%) between pIC $24 \mathrm{HPI} @ 10^{\circ} \mathrm{C}$ and pIC $24 \mathrm{HPI} @ 16^{\circ} \mathrm{C}$ only ${ }^{2}$} \\
\hline Probe ID & Best BLASTx hit $^{3}$ & $\begin{array}{l}\text { Fold-change } \\
\text { (pIC @ } 16^{\circ} \mathrm{C} / \\
\left.\text { PBS @ } 16^{\circ} \mathrm{C}\right)^{4}\end{array}$ & $\begin{array}{l}\text { Fold-change } \\
\left(p I C @ 10^{\circ} \mathrm{C} /\right. \\
\left.\text { PBS @ } 10^{\circ} \mathrm{C}\right)^{4}\end{array}$ & $\begin{array}{l}\text { Fold-change } \\
\left(p I C @ 16^{\circ} \mathrm{C} /\right. \\
\left.\text { plC @ } 10^{\circ} \mathrm{C}\right)^{4}\end{array}$ \\
\hline 37555 & Heat shock protein 47 [Oncorhynchus mykiss] & - & - & 1.77 \\
\hline 40546 & Heat shock protein HSP 90-alpha [Harpegnathos saltator] & - & - & 1.64 \\
\hline 36470 & Chaperonin containing TCP1 subunit 6A [Paralichthys olivaceus] (Alias: CCT6) & - & - & 1.54 \\
\hline 44902 & HSP90 multi-domain protein (pfam 00183) & - & - & 1.47 \\
\hline 37544 & Heat shock cognate protein 70 [Pelodiscus sinensis] (Alias: HSC71) & - & - & 1.35 \\
\hline 42467 & TANK-binding kinase 1 [Gadus morhua] & - & - & -1.37 \\
\hline 37203 & Ferritin heavy subunit [Epinephelus awoara] & - & - & -1.47 \\
\hline 41479 & Protein kinase $C$, delta [Danio rerio] & - & - & -1.47 \\
\hline
\end{tabular}

${ }^{1}$ Probes presented in this table were selected based on their known roles in vertebrate immune responses. Some genes without a BLASTx hit (e.g. Unknowns) were added because they presented a pIC-induced fold-change higher than 5, and therefore, could represent novel immune-relevant genes. For a complete list of microarray-identified informative probes please refer to Additional file 1: Tables S2-S5 and S7-S8.

${ }^{2}$ Fold-change in probe expression is also shown for pIC @ $16^{\circ} \mathrm{C}$ vs. pIC @ $10^{\circ} \mathrm{C}$ when significant differential expression was found in the PBS vs. pIC comparisons. ${ }^{3}$ Informative genes were re-annotated using the contig or EST from which the probe printed in the array was designed by comparing the referred sequence to the NCBI's nr database using the BLASTx algorithm as implemented by Blast2GO [67]. The best BLASTx hit (E-value cutoff of $10^{-5}$ ) with an informative name (i.e. not predicted, probable or unnamed protein) is presented in this table. Synonyms were obtained from SWISS-PROT, GENE CARDS other BLASTx hits as long as they had E-value $<10^{-5}$, or from the literature ('Borza et al. [58]). Some genes without a BLASTx hit (e.g. Unknowns) were added because they presented a pIC induced fold-change higher than 5 , and therefore, could represent novel immune-relevant genes.

${ }^{4}$ Fold-changes are only reported when probes were differently expressed (FDR $=1 \%$ ) in a given comparison (e.g. pIC@10 ${ }^{\circ} \mathrm{C}$ vs. pIC@16 $16^{\circ} \mathrm{C}$ ) and are shown as outputted by siggenes; otherwise a dash (-) is presented in place of the fold-change. Fold-change values preceded by a minus ("- $\left.{ }^{\prime \prime}\right)$ sign represent overall fold down-regulation for a particular comparison. For standard deviation, p- and d-values, please refer to Additional file 1: Tables S2-S5 and S7-S8. 


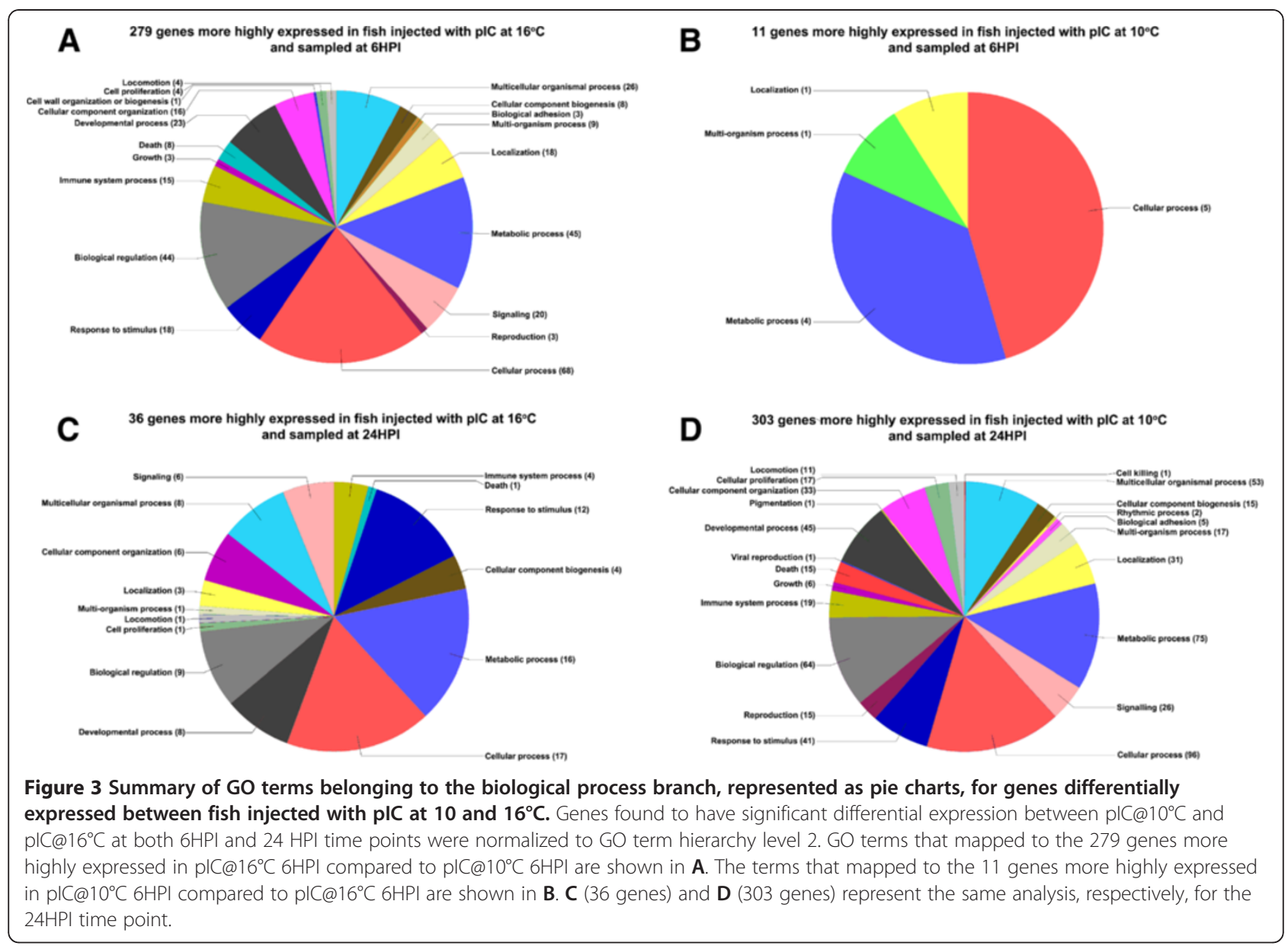

at the same time point. This is likely a reflection of the low number of probes in this particular gene list. Fifteen of the level 2 biological process GO terms that were mapped to the genes more highly expressed in fish stimulated with pIC at $16^{\circ} \mathrm{C}$ and sampled at $6 \mathrm{HPI}$ were also mapped to the genes that were more highly expressed in fish stimulated with $\mathrm{pIC}$ at $10^{\circ} \mathrm{C}$ and sampled at 24HPI (each compared to its time-matched pIC injected counterpart); we also found that 96 probes were present in both gene lists (Figure 4) (Additional file 1: Table S9). However, many of the GO terms that were in common between these lists had more sequences mapped to them in the list of probes more highly expressed in fish stimulated with $\mathrm{pIC}$ at $10^{\circ} \mathrm{C}$ and sampled at 24HPI compared to the time-matched fish stimulated with $\mathrm{pIC}$ at $16^{\circ} \mathrm{C}$. Examples are signaling (20 for pIC 6HPI@ $16^{\circ} \mathrm{C}$ and 26 for pIC 24HPI@10 $0^{\circ} \mathrm{C}$, immune system process $\left(15\right.$ for pIC $6 \mathrm{HPI} @ 16^{\circ} \mathrm{C}$ and 19 for pIC $24 \mathrm{HPI} 10^{\circ} \mathrm{C}$ ), death (8 for pIC 6HPI@ $16^{\circ} \mathrm{C}$ and 15 for pIC 24HPI@10 $10^{\circ} \mathrm{C}$ ), biological regulation (44 for pIC $6 \mathrm{HPI} 16^{\circ} \mathrm{C}$ and 64 for pIC $24 \mathrm{HPI} @ 10^{\circ} \mathrm{C}$ ), response to stimulus (18 for pIC 6HPI@ $16^{\circ} \mathrm{C}$ and 41 for pIC $\left.24 \mathrm{HPI} 10^{\circ} \mathrm{C}\right)$ and cellular process (68 for pIC $6 \mathrm{HPI} 16^{\circ} \mathrm{C}$ and 96 for pIC 24HPI@10 ${ }^{\circ} \mathrm{C}$ ).

The GO enrichment analysis also identified several GO terms with significantly different over-/under-representation between the genes up-regulated by pIC (relative to PBS) at 24HPI at the two temperatures. Most GO terms (55 out of 57) identified were over-represented in the genes up-regulated by $\mathrm{pIC}$ at $16^{\circ} \mathrm{C}$ compared with those up-regulated by $\mathrm{pIC}$ injection at $10^{\circ} \mathrm{C}$ (all relative to PBS). Examples of these over-represented GO terms in the $24 \mathrm{HPI}$ list of $\mathrm{pIC}$ responsive genes at $16^{\circ} \mathrm{C}$ are: protein folding (GO:0006457), negative regulation of cellular process (GO:0048523), negative regulation of protein metabolic process (GO:0051248), regulation of interferon-gamma-mediated-signaling (GO:0060334), regulation of signaling process (GO:0023051), regulation of signal transduction (GO:0009966), regulation of cytokinemediated signaling pathway (GO:0001959), unfolded protein binding (GO:0051082) and enzyme regulatory activity (GO:0030234). Two GO terms were under- 


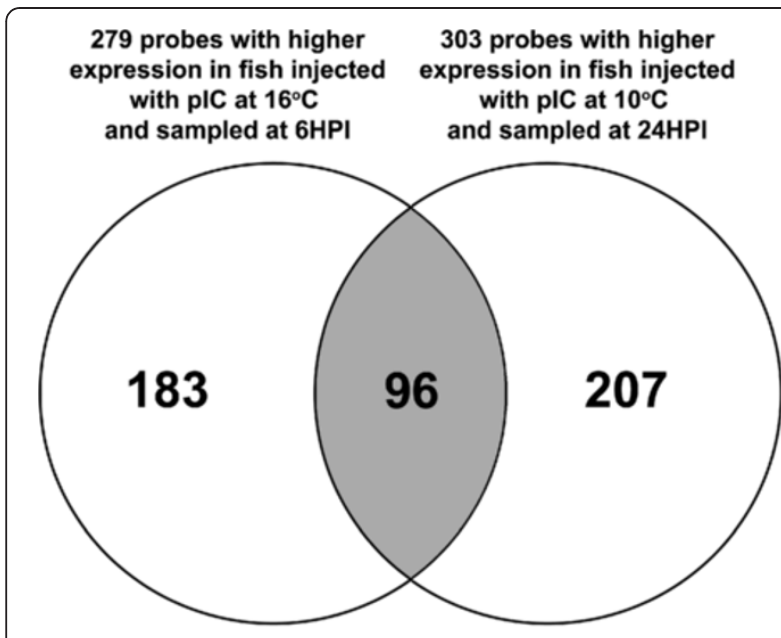

Figure 4 Venn diagram showing the overlap between the genes with significantly higher mRNA expression in pIC@16 ${ }^{\circ} \mathrm{C}$ $6 \mathrm{HPI}$ compared to pIC@10 $\mathrm{C} 6 \mathrm{HPI}$ and those with significantly higher mRNA expression in pIC @1 $10^{\circ} \mathrm{C} 24 \mathrm{HPI}$ compared to pIC@16ㄷ 24HPI.

represented in the $24 \mathrm{HPI}$ list of pIC responsive genes at $16^{\circ} \mathrm{C}$ : macromolecule modification (GO:0043412) and protein modification process (GO:0006464).

We present 2 separate clustering results displayed as heat-maps (Figures 5, 6 and 7). In these heat-maps, all individuals (60) were clustered based on their expression for the genes identified as differentially expressed between the pIC@ $16^{\circ} \mathrm{C}$ and pIC@ $10^{\circ} \mathrm{C}$ groups at $6 \mathrm{HPI}$ (Figure 5) or at 24HPI (Figure 6 and 7). In Figure 5, panel A shows the entire heat-map for the 6HPI time point, while panel $\mathrm{B}$ shows a sub-tree (marked as a blue bar on the right of panel A) dominated by genes belonging to the interferon (IFN) pathway. Figure 6 shows the entire heat-map for the 24HPI time point, while Figure 7 shows a sub-tree (marked as a blue bar on the right of Figure 6) dominated by genes belonging to the interferon (IFN) pathway. Both clustering results show a clear distinction (with a few outliers) between the groups of fish injected with $\mathrm{pIC}$ at the different temperatures and time points. Based on the expression of the genes identified in the above-mentioned comparisons, the pIC, $6 \mathrm{HPI} @ 10^{\circ} \mathrm{C}$ group had an expression profile more similar to that of the non-pIC stimulated fish, while the pIC, 6HPI @ $16^{\circ} \mathrm{C}$ group's expression profile was more similar to that of the pIC, 24HPI $@ 10^{\circ} \mathrm{C}$ group. For the non-pIC stimulated fish (including the PBS-injected and non-injected groups), the clusters were less distinctive.

\section{QPCR validation of selected immune-relevant genes}

Genes of interest (GOI) were selected for QPCR analysis based on their putative roles in pathogen detection, signal transduction/transcription control and as immune effectors; the QPCR data is presented in Figures 8, 9, and 10 , respectively, as average $\log _{2}$ transformed relative quantities $(\mathrm{RQs}) \pm \mathrm{SE}$. Fifteen of the immune-relevant genes (88\%; all except TLR3 and IRAK4) were validated as being significantly $(\mathrm{P}<0.05)$ differentially expressed in at least one comparison (e.g. pIC 6HPI@ $10^{\circ} \mathrm{C}$ vs. PBS $6 \mathrm{HPI} 10^{\circ} \mathrm{C}$ ) from which they were identified as informative probes in the microarray experiment. There are several possible explanations for disagreement between microarray and QPCR results (e.g. differences between location of QPCR amplicon and microarray probe or possible misassembly of contigs, for more details see the discussion of Booman et al. [21]). For TLR3 and IRAK4 in the current study, there may have been related sequences (e.g. paralogs) binding to these probe in the array and influencing hybridization results. Also, the fact that 3 of the individuals used in the QPCR experiment were not part of the microarray experiment may have contributed to the disagreement between microarray and QPCR results for these two genes. Of the 4 genes with putative pathogen detection roles that were subjected to QPCR, 3 (TLR9, PKR, and DHX58) were validated (i.e. showed a significant difference in at least one of the group comparisons corresponding to the microarray comparison identifying the genes as differentially expressed). In the QPCR experiment for genes potentially involved in pathogen detection, DHX58 showed the highest fold upregulation in response to pIC (13.00-fold at 6 HPI@ $16^{\circ} \mathrm{C}$ and 34.86 -fold at $24 \mathrm{HPI} @ 10^{\circ} \mathrm{C}$ ) and the highest fold differential expression between fish injected with pIC at different temperatures (at 6HPI DHX58 was 13.64-fold more highly expressed in fish injected with pIC at $16^{\circ} \mathrm{C}$, and at $24 \mathrm{HPI}$ it was 4.45 -fold more highly expressed in fish injected with $\mathrm{pIC}$ at $10^{\circ} \mathrm{C}$ ) (Figure 8D). PKR showed the same trend but with lower, and yet significant, foldchanges (at 6HPI, 1.56-fold higher in pIC@ $16^{\circ} \mathrm{C}$ vs. PBS@16 ${ }^{\circ} \mathrm{C}$ and 1.86-fold higher in pIC@16 $\mathrm{C}$ vs. pIC@10 $\mathrm{C}$; at $24 \mathrm{HPI}, 2.73$-fold higher in pIC@ $10^{\circ} \mathrm{C}$ vs. PBS@10 $\mathrm{C}$ and 1.65-fold higher in pIC@16 ${ }^{\circ} \mathrm{C}$ vs. PBS@16 ${ }^{\circ} \mathrm{C}$ ).

Of the 8 microarray-identified genes with putative roles in signal transduction/transcription control analyzed with QPCR, 7 (IkB $\alpha$, IRF1, IRF7, IRF10, STAT1, Deltex3, ZNFX1) were validated. QPCR analysis showed that I $\kappa \mathrm{B} \alpha$ mRNA was only differentially expressed between groups at the 6HPI time point (Figure 9A: 3.82fold higher in pIC@10 $10^{\circ} \mathrm{C}$ v. PBS@10 $\mathrm{C}$, 1.94-fold higher in pIC@16 $6^{\circ} \mathrm{C}$ v. PBS@ $16^{\circ} \mathrm{C}$ and 1.69-fold higher in pIC@ $10^{\circ} \mathrm{C}$ vs. pIC@ $16^{\circ} \mathrm{C}$ ). All three studied transcripts encoding interferon regulatory factors (IRFs - 1, 7, and 10, Figure 9B, C and D, respectively) showed very similar expression profiles at the mRNA level. These genes responded significantly to $\mathrm{pIC}$ at both temperatures and time points, although the magnitude of the fold up- 


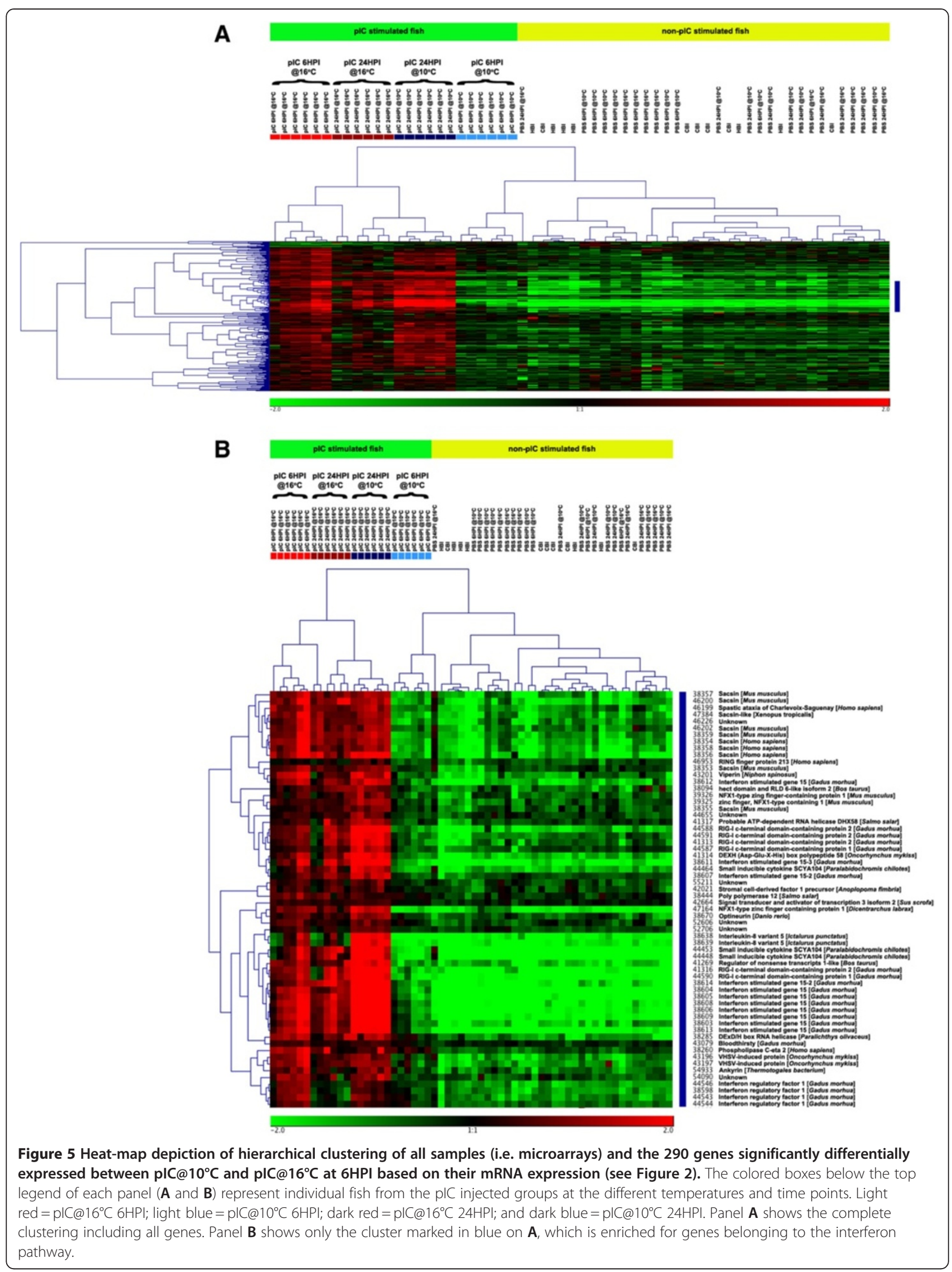




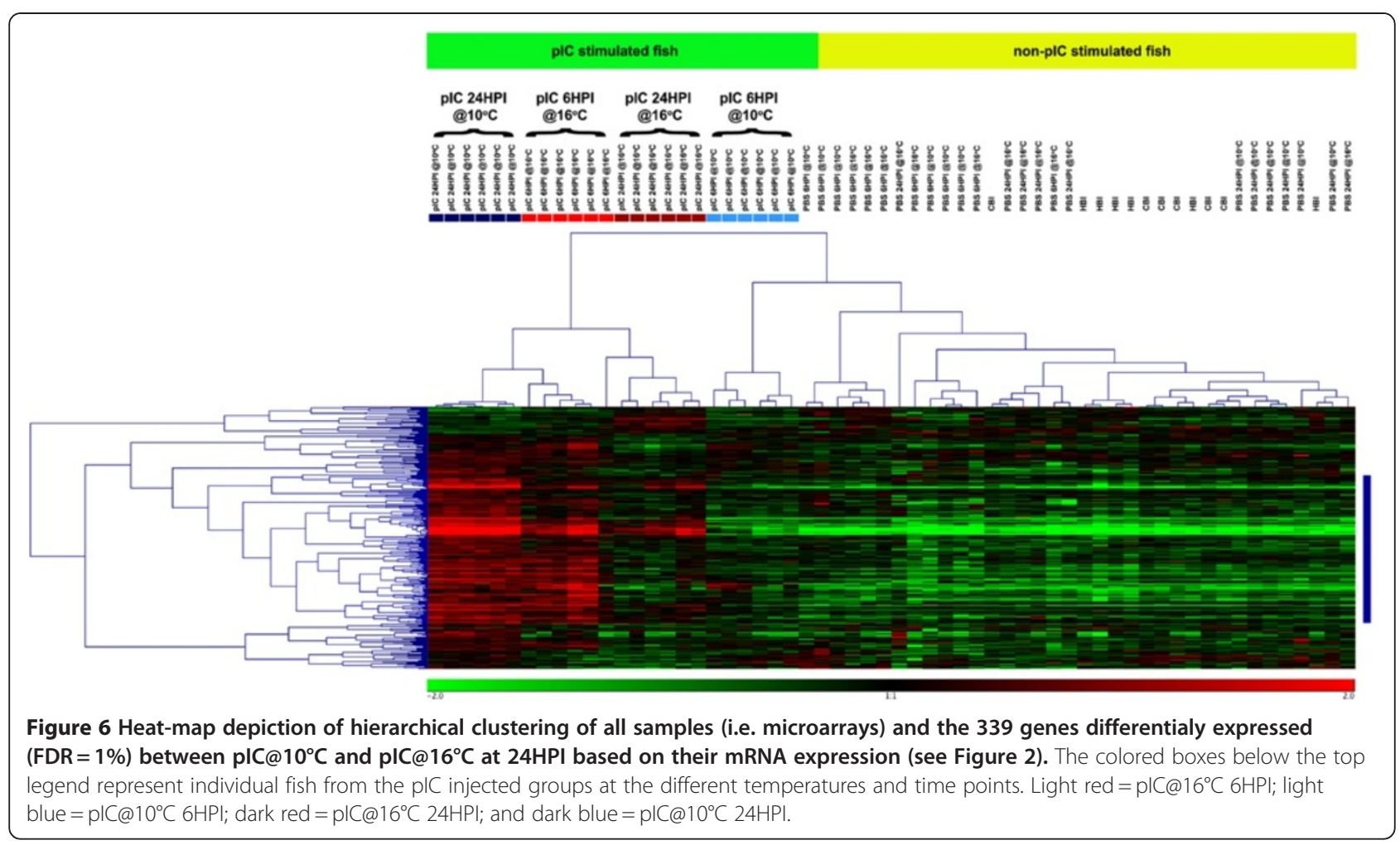

regulation was variable. Of all studied IRFs, IRF7 at the $6 \mathrm{HPI}$ time point showed the highest response to pIC (13.26-fold at $\left.16^{\circ} \mathrm{C}\right)$ and the highest fold difference between fish injected with pIC at 16 vs. $10^{\circ} \mathrm{C}$ (4.66-fold). At the 24HPI time point, IRF10 showed the highest response to pIC $\left(9.07\right.$-fold at $\left.10^{\circ} \mathrm{C}\right)$ and the highest fold difference between fish injected with pIC at 10 vs. $16^{\circ} \mathrm{C}$ (4.47-fold). Of all the genes with putative roles in signal transduction/transcription control, ZNFX1 showed the highest response to $\mathrm{pIC}$ at $10^{\circ} \mathrm{C}$ (Figure $9 \mathrm{H}: 15.30$ fold up-regulation at 24HPI). As previously mentioned, the microarray results for IRAK4 (Tables 1 and 2) were not validated by QPCR analysis (Figure 9F).

All 5 of the putative immune-effector genes studied with QPCR showed significant differential expression at 6HPI and 24HPI between fish injected with pIC vs. PBS at 10 and/or $16^{\circ} \mathrm{C}$ (Figure 10A-E). Further, they showed the highest fold-changes of all the transcripts studied with QPCR. At 6HPI, ISG15 showed the highest response to $\mathrm{pIC}$ at both temperatures $\left(20.77\right.$-fold at $10^{\circ} \mathrm{C}$ and 134.8 -fold at $16^{\circ} \mathrm{C}$ ), and RSAD2 (alias viperin) (Figure 10E) showed the highest differential mRNA expression between fish injected with $\mathrm{pIC}$ at the two temperatures $\left(13.47\right.$-fold higher in $16^{\circ} \mathrm{C}$ vs. $\left.10^{\circ} \mathrm{C}\right)$. At $24 \mathrm{HPI}$, ISG15 also showed the highest response to pIC at both temperatures $\left(155.2\right.$-fold at $10^{\circ} \mathrm{C}$ and 82.40 -fold at $16^{\circ} \mathrm{C}$ ) (Figure 10C), while IL-8 presented the highest fold difference between fish stimulated with pIC at 10 vs. $16^{\circ} \mathrm{C}$ (11.14-fold higher at $10^{\circ} \mathrm{C}$ ) (Figure 10B). ISG15 was the only microarray identified, QPCR studied putative immune-effector transcript for which not all differences detected on the microarray were validated by QPCR. While ISG15 was identified as being differently expressed $(\mathrm{FDR}=1 \%)$ between fish injected with $\mathrm{pIC}$ at 10 vs. $16^{\circ} \mathrm{C}$ at $24 \mathrm{HPI}$ in the microarray experiment, only a non-significant change in the same direction was observed in the QPCR at 24HPI.

\section{Discussion}

Variations in temperature are an inevitable element of cage-site based aquaculture $[8,32,33]$. We used a regimen of gradual increases in water temperature that simulated the environmental conditions to which the farmed Atlantic cod can be exposed during the springsummer transition in sea-cages in Newfoundland, and microarrays and QPCR to study the impact of changes in rearing temperature on the spleen anti-viral transcriptome response of cod. Several studies [34-36] have used functional genomics approaches to study the individual impact of stress or immune stimulation on fish transcriptomes; however, to our knowledge, the current study is the first to use global gene expression analysis to investigate the impact of elevated water temperature on the anti-viral immune transcriptome of a fish species. We were able to demonstrate at the mRNA level that, while a gradual non-lethal increase in water temperature from $10^{\circ} \mathrm{C}$ to $16^{\circ} \mathrm{C}$ only caused minor changes in the spleen transcriptome, it had a major influence on the 


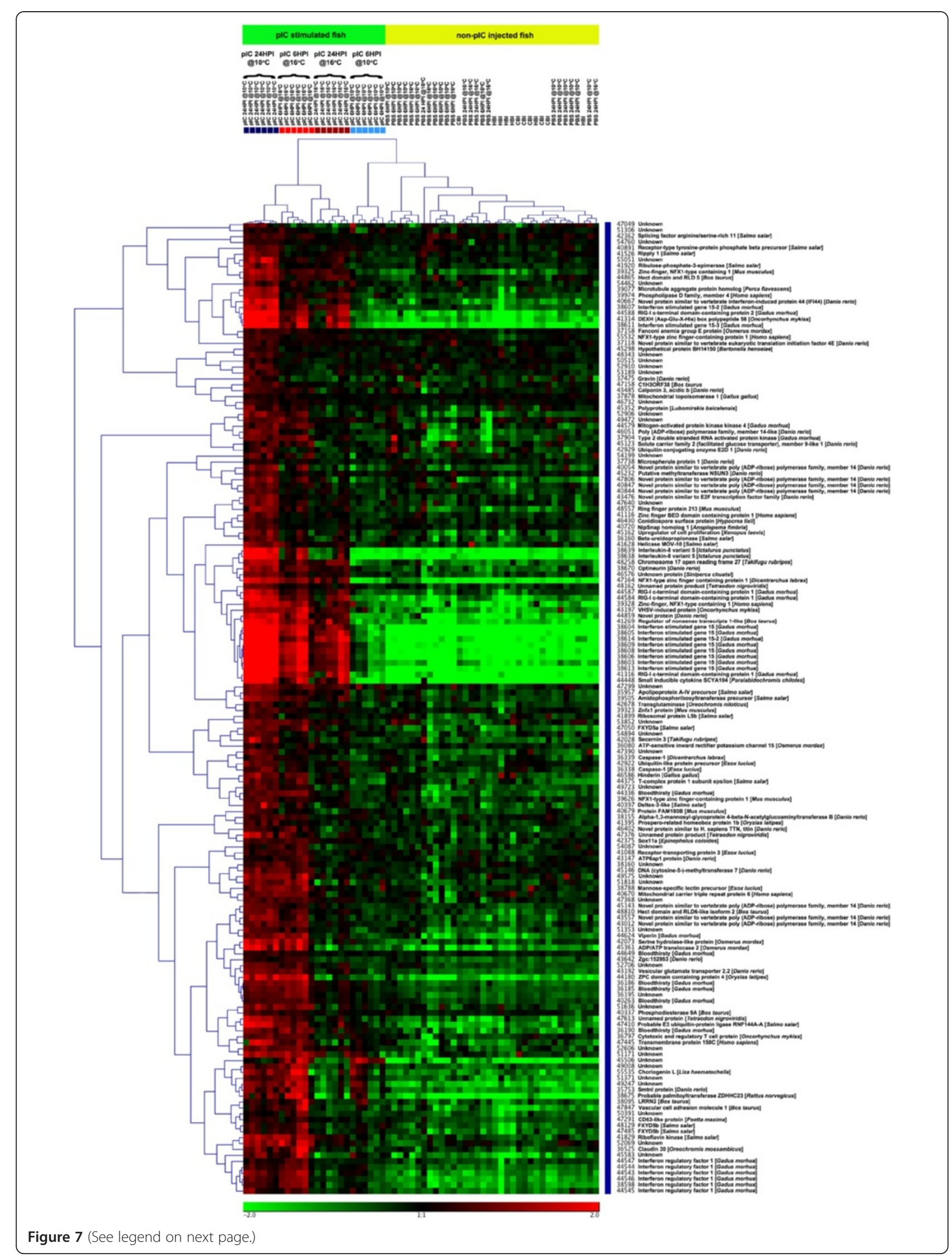


(See figure on previous page.)

Figure 7 Detail of a sub-tree (marked in blue on Figure 6) from the hierarchical clustering of all samples (i.e. microarrays) and the 339 genes differentialy expressed (FDR = 1\%) between pIC@10 ${ }^{\circ} \mathrm{C}$ and pIC@ $16^{\circ} \mathrm{C}$ at $24 \mathrm{HPI}$ based on their mRNA expression (see Figures 2 and 6) enriched for genes belonging to the interferon pathway. The colored boxes below the top legend represent individual fish from the plC injected groups at the different temperatures and time points. Light red=plC@16 ${ }^{\circ} \mathrm{C} 6 \mathrm{HPl}$; light blue=plC@10 $6 \mathrm{HPl}$; dark red=plC@16 ${ }^{\circ} \mathrm{C}$ $24 \mathrm{HPl}$; and dark blue=plC@10² $24 \mathrm{HPI}$.

cod spleen gene expression response to IP injection with the viral mimic pIC.

\section{Influence of elevated temperature on plasma cortisol and the spleen transcriptome}

In the present study, plasma cortisol levels did not increase significantly when cod were exposed to the increasing temperature regimen. This finding suggests that our juvenile cod were not stressed under these conditions, and that the differences observed in the pIC response of fish exposed to elevated temperatures may not have been the result of transcriptional changes driven by the glucocorticoid receptor (GR). However, this is in contrast to the results of Pérez-Casanova et al. [9] who reported plasma cortisol values of $\sim 52 \mathrm{ng} \mathrm{ml}^{-1}$ in similar sized cod that had been warmed from $10^{\circ} \mathrm{C}$ to $16^{\circ} \mathrm{C}$ using a similar protocol. This discrepancy is likely due to the fact that Pérez-Casanova et al. [9] sampled their fish as temperature reached $16^{\circ} \mathrm{C}$, whereas we sampled the cod after they were given a week to acclimate to this temperature. It is probable that the extra week to which our fish were exposed to $16^{\circ} \mathrm{C}$ allowed their cortisol (stress) level to return towards basal values. This hypothesis is also supported by Pérez-Casanova et al. [9], as these authors reported that cod plasma cortisol levels decreased on day 40 of their experiment (temperature $\sim 17^{\circ} \mathrm{C}$ ) and that values remained at pre-stress levels as temperature was increased further.

Increasing water temperature to $16^{\circ} \mathrm{C}$ alone had a very small impact on the cod spleen transcriptome (only 6 up-regulated genes were detected at FDR $=1 \%$, Figure 2). Using microarrays, we were unable to detect any differential expression of $\beta 2$-microglobulin, MHC-I or IgM heavy chain transcripts due to increases in water temperature alone. This result is again different from the results of Pérez-Casanova et al. [9] who showed, using QPCR with blood cDNA templates, that these genes were differentially expressed between cod at $16^{\circ} \mathrm{C}$ and at $10^{\circ} \mathrm{C}$. Although we cannot rule out tissue-specific differences (spleen vs. blood) in the response of these genes to the temperature increase, it is also possible that the different sampling regimes (see above) could explain these disparate findings. When this data is combined with that for plasma cortisol levels, it suggests that prolonged exposure of Atlantic cod juveniles to sea-cage temperatures of $16^{\circ} \mathrm{C}$ (in the absence of immune challenge) is unlikely to have negative consequences with regards to their stress state or basal immune transcript expression.

\section{Temperature effects on the Atlantic cod spleen anti-viral transcriptome}

Compared to the time- and temperature-matched PBS controls, pIC altered the expression of 41 (37 upregulated and 4 down-regulated) and 999 (851 upregulated and 148 down-regulated) transcripts in $10^{\circ} \mathrm{C}$ fish at 6HPI and 24HPI, respectively, and 656 (617 upregulated and 39 down-regulated) and 246 (243 upregulated and 3 down-regulated) transcripts in $16^{\circ} \mathrm{C}$ fish at $6 \mathrm{HPI}$ and $24 \mathrm{HPI}$, respectively (Figure 2). Figure 3 shows a summary of the GO terms that were associated with the genes differentially expressed between fish injected with $\mathrm{pIC}$ at the different temperatures and sampled at 6HPI (Figure 3A-B) and 24HPI (Figure 3CD). Not surprisingly, immune system process, signaling and response to stimulus were found in 3 out of the 4 pie charts in relatively high proportions (Figure 3A, C and D). These results indicate, as previous reports have shown $[7,11,12,14]$, that elevated temperatures can induce changes in the fish's immune response to an antigen. Furthermore, we suggest that the genes associated with these GO terms (e.g. biological regulation, death, growth, metabolic process; see Figure 3) may be good candidates for the development of molecular markers [e.g. exonic, intronic or regulatory region single nucleotide polymorphisms (SNPs)] to be used in marker assisted selection (MAS) programs aimed at developing elite broodstock (e.g. resistant to potentially negative impacts of elevated temperature on immune response) for the Atlantic cod aquaculture industry.

The sample clustering based on genes differentially expressed between the groups injected with $\mathrm{pIC}$ and sampled at 6HPI shows that the expression profile of pIC injected fish held at $10^{\circ} \mathrm{C}$ and sampled at $6 \mathrm{HPI}$ was most similar to that of the non-immune stimulated (i.e. non-injected or injected with PBS) fish than to the profile of any other group of fish injected with pIC (i.e. pIC $6 \mathrm{HPI} @ 16^{\circ} \mathrm{C}$, pIC $24 \mathrm{HPI} @ 10^{\circ} \mathrm{C}$ and pIC 24HPI@16 $\mathrm{C}$ ) (Figure 5A). In addition, clustering based on the 339 genes differentially expressed between fish injected with 


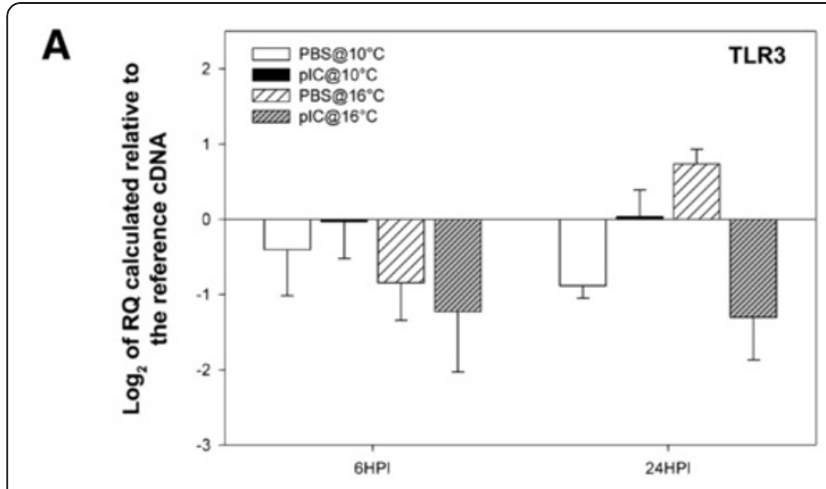

Fold-change (pIC/PBS):

Fold-change $\left(16^{\circ} \mathrm{C} / 10^{\circ} \mathrm{C}\right)$ :

B

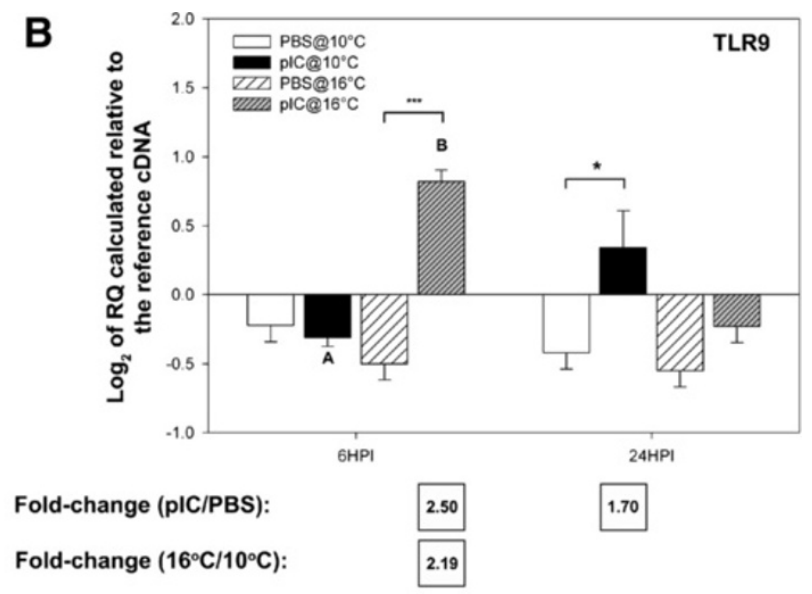

C

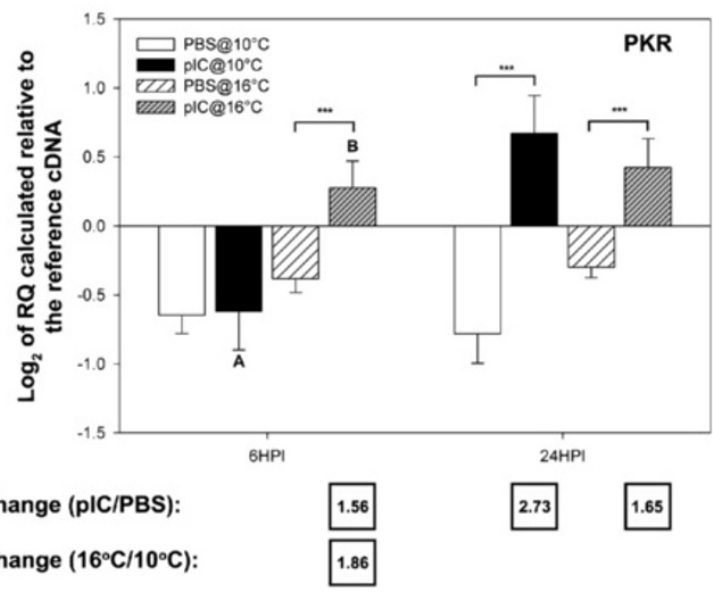

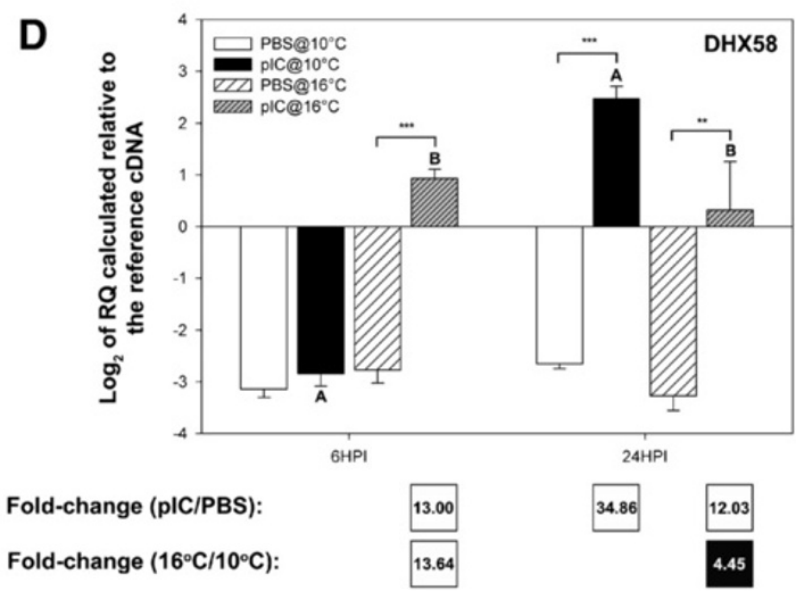

Fold-change $\left(16^{\circ} \mathrm{C} / 10^{\circ} \mathrm{C}\right)$ :

Figure 8 QPCR results for transcripts with putative roles in the detection of a pathogen (see Additional file 2: Figure S1 schema of the TLR/interferon pathways). Data is presented as mean $\log _{2}$ transformed data \pm SE. Different letters represent significant differences between fish injected with plC at different temperatures within each time point. An asterisk $\left(^{*}\right)$ represents a difference between a given plC-injected group and the time- and temperature-matched PBS-injected group ( ${ }^{*} p<0.05$; $\left.{ }^{* *} p<0.01 ; *^{* *} p<0.001\right)$. Fold-changes in white boxes are always plC/PBS or $16^{\circ} \mathrm{C} / 10^{\circ} \mathrm{C}$, and are shown in the boxes beneath each panel. Only significant differences are shown. Black boxes show $1 /$ fold-change for comparisons that yielded fold-change values less than one (for more details on fold-change calculations, refer to the methods section). For example, if white boxes (i.e. black numbers on white background) show $16^{\circ} \mathrm{C} / 10^{\circ} \mathrm{C}$ fold change then a black box would show $10^{\circ} \mathrm{C} / 16^{\circ} \mathrm{C}$ fold change. A) TLR3; B) TLR9; C) PKR; D) DHX58.

$\mathrm{pIC}$ at the different temperatures and sampled at 24HPI (Figures 6 and 7), indicates that the mRNA expression profile of pIC-injected fish held at $16^{\circ} \mathrm{C}$ and sampled 6HPI was most similar to that of fish injected with pIC at $10^{\circ} \mathrm{C}$ and sampled at $24 \mathrm{HPI}$. Collectively, these data suggest that the moderate increase in water temperature caused a time shift in the transcriptomic response of cod spleen to $\mathrm{pIC}$, with fish held at elevated temperature $\left(16^{\circ} \mathrm{C}\right)$ having an earlier maximum response (i.e. at $6 \mathrm{HPI})$ than fish held at optimal temperature $\left(10^{\circ} \mathrm{C}\right)$, which had a later maximum response (i.e. at 24HPI). Raida and Buchmann [11] report similar data for mRNA expression of immune-relevant genes in the spleen of rainbow trout injected with a Yersinia ruckeri bacterin. These authors found that peak transcript expression of IL-1 $\beta$, IL-10 and IFN- $\gamma$ happened earlier in fish stimulated at $15^{\circ} \mathrm{C}$ or $25^{\circ} \mathrm{C}$ when compared to fish stimulated at $5^{\circ} \mathrm{C}$. Furthermore, it is clear from our heatmaps that, overall, the magnitude of response to pIC for these genes was greatest in the $\mathrm{pIC}$ stimulated fish at $10^{\circ}$ $\mathrm{C}$ and sampled at 24HPI. This result, however, must be interpreted with caution. Our results suggest that holding cod at $16^{\circ} \mathrm{C}$ may result in a faster, but weaker, immune response to a viral mimic; this hypothesis could be tested in the future by sampling pIC-injected cod exposed to similar temperature regimes at more frequent intervals post-injection. In future research, more frequent sampling (e.g. every 2 hours post-injection) may allow one to determine if the maximum induction of pIC responsive genes that we observed in the fish held at elevated temperature $\left(16^{\circ} \mathrm{C}\right)$ and sampled 6 hours after pIC-injection is the peak response, which would 


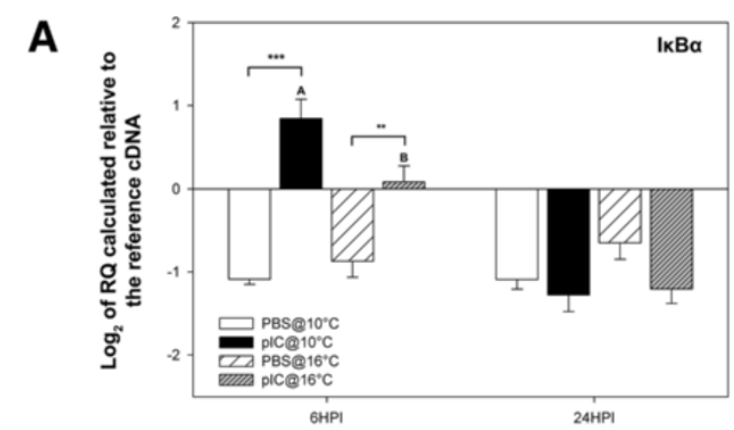

Fold-change (pIC/PBS): $3.82 \quad 1.94$

Fold-change $\left(16^{\circ} \mathrm{C} / 10^{\circ} \mathrm{C}\right)$ :

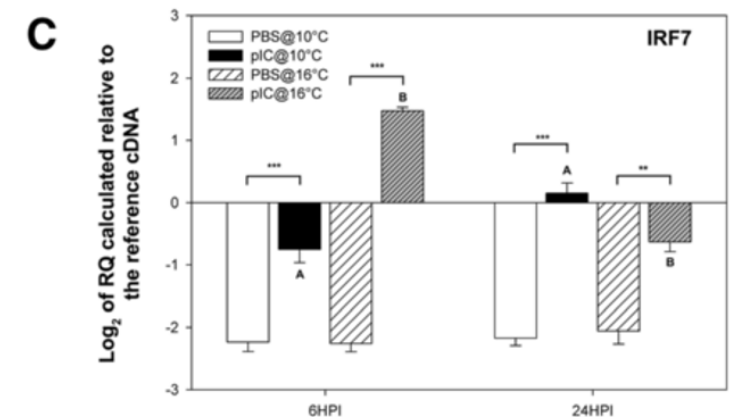

\begin{tabular}{lllll|} 
Fold-change (pIC/PBS): & 2.80 & 13.26 & 5.01 & 2.69 \\
\hline Fold-change $\left(16^{\circ} \mathrm{C} / 10^{\circ} \mathrm{C}\right):$ & 4.66 & & 1.72 \\
\hline
\end{tabular}

E

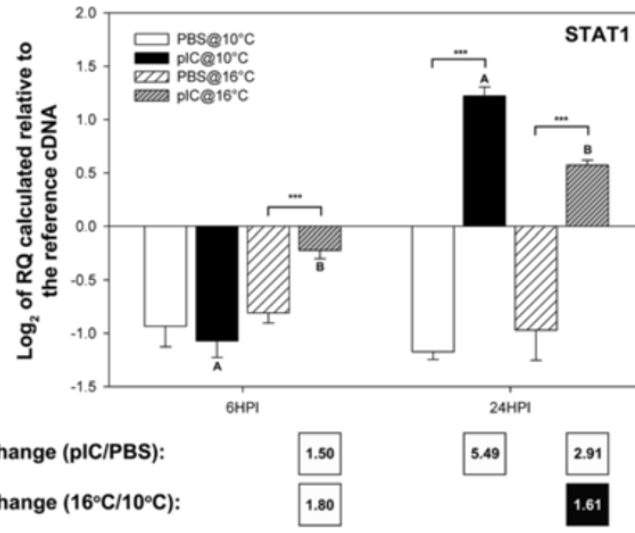

\section{G}

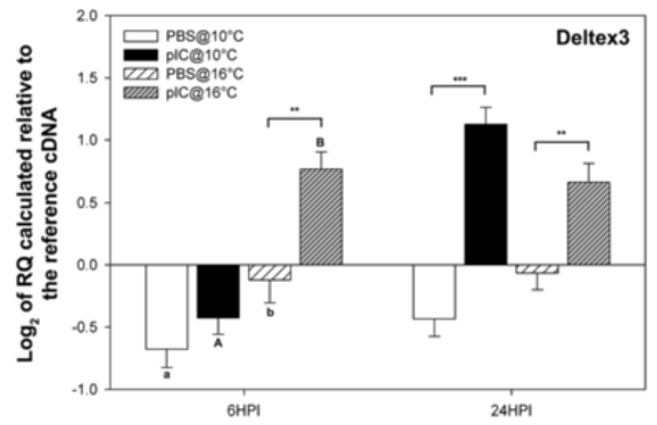

Fold-change (pIC/PBS):

\begin{tabular}{|l|l|}
\hline 1.85 \\
\hline 1.47 & 2.29 \\
\hline
\end{tabular}

$2.95 \quad 1.66$
B

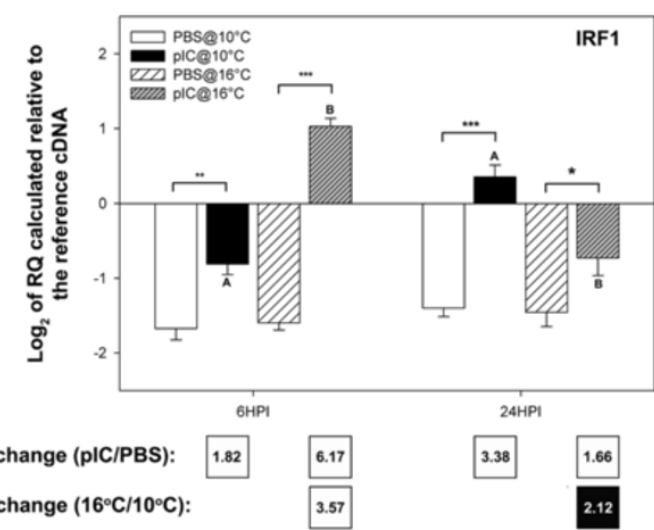

D

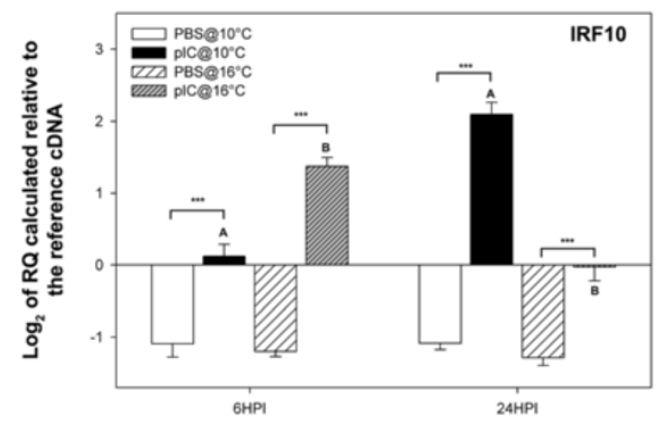

Fold-change (pIC/PBS)

2.32

\begin{tabular}{|l|}
\hline 5.94 \\
\hline 2.39 \\
\hline
\end{tabular}

$2.07 \quad 2.39$

Fold-change $\left(16^{\circ} \mathrm{C} / 10^{\circ} \mathrm{C}\right)$ :

4.47

F

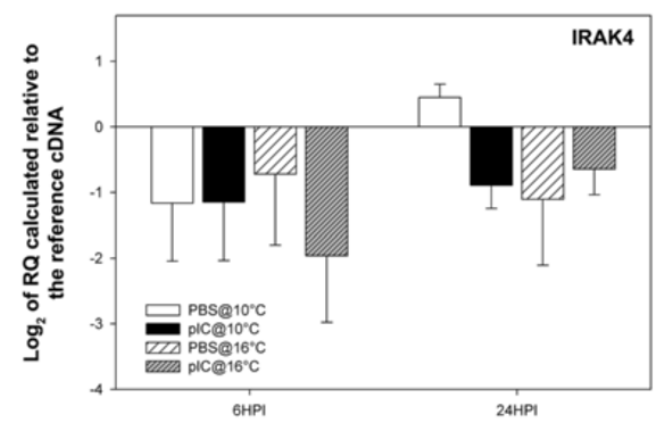

Fold-change (pIC/PBS):

Fold-change $\left(16^{\circ} \mathrm{C} / 10^{\circ} \mathrm{C}\right)$ :

H

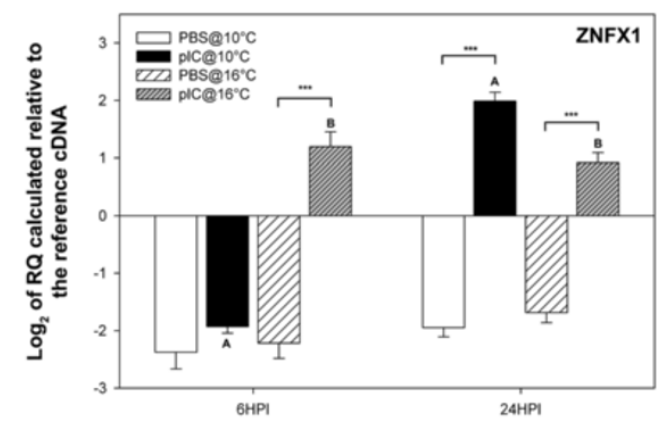

\begin{tabular}{llll} 
Fold-change (PIC/PBS): & 10.65 & 15.30 & 6.09 \\
\hline Fold-change $\left(16^{\circ} \mathrm{C} / 10^{\circ} \mathrm{C}\right):$ & 8.73 & & 2.10
\end{tabular} 
(See figure on previous page.)

Figure 9 QPCR results for transcripts with putative roles in signal transduction/transcription control (see Additional file 2: Figure S1 schema of the TLR/interferon pathways). Data is presented as mean $\log _{2}$ transformed data \pm SE. Different letters represent significant differences between fish injected with pIC at different temperatures within each time point. An asterisk $\left(^{*}\right)$ represents a difference between a given plC-injected group and the time- and temperature-matched PBS-injected group ${ }^{*} p<0.05 ;{ }^{* *} p<0.01$; *** $p<0.001$ ). Fold-changes in white boxes are always plC/PBS or $16^{\circ} \mathrm{C} / 10^{\circ} \mathrm{C}$ and are shown in the boxes beneath each panel. Only significant differences are shown. Black boxes show 1/fold-change for comparisons that yielded values less than one (for more details on fold-change calculations, refer to the methods section). For example, if white boxes (i.e. black numbers on white background) show plC/PBS fold change then a black box (i.e. white numbers on black background) would show PBS/plC fold change. A) IKBa; B) IRF1; C) IRF7; D) IRF10; E) STAT1; F) IRAK4; G) Deltex3; H) ZNFX1.

indicate that there is indeed a weaker maximal pIC response in these fish compared with fish held at optimal temperature $\left(10^{\circ} \mathrm{C}\right)$. However, if peak spleen transcript expression response to pIC occurs before or after 6HPI for fish held at elevated temperature, and before or after 24HPI for fish held at optimal temperature, this could be determined in future studies incorporating more frequent post-injection sampling.

Using the clustering of genes based on their expression profiles for each sample, we were able to identify many different clusters, including one from each time point that is highly enriched for putative members of the interferon pathway. These clusters are marked in blue on Figures 5A and 6 and shown in detail in Figures 5B and 7. The interferon pathway is a key part of the fish innate response to viruses $[20,22,25,37,38]$, and our results indicate that elevated temperature had a considerable impact on the cod innate immune response to a viral mimic.

\section{Impacts of the gradual temperature increase on transcript expression \\ Genes with putative viral detection roles}

One of the key steps in mounting an anti-viral innate immune response (e.g. expression of type I interferons and proinflammatory cytokines) is the detection of an invading pathogen. This recognition often occurs via the detection of a set of pathogen associated molecular patterns (PAMPs). PAMPs bind specifically to germ-line pattern recognition receptors (PRRs), which in turn activate signaling pathways that induce the innate immune response [39-41]. The immune-stimulant used in this experiment (pIC) is a double-stranded RNA (dsRNA) that mimics the genome and/or RNA intermediates of several viruses and is recognized by PRRs, including the Toll-like receptor 3 (TLR3). Several genes putatively belonging to the TLR pathway (e.g. TLR3) have been identified in fish [36,41] (see Additional file 2: Figure S1 for a schema of a putative type I IFN activation via TLRs pathway in Atlantic cod). While TLR3-like transcript was shown to be slightly up-regulated by pIC in $16^{\circ} \mathrm{C}$ fish at $6 \mathrm{HPI}$ on the microarray (1.32 fold - Table 1), the QPCR analysis did not confirm this result (Figure 8A). In fact, we did not detect any significant changes in TLR3 transcript due to pIC injection using QPCR. This is not surprising as Rise et al. [22] obtained similar QPCR results for TLR3 (using the same primer pair) in spleens from cod stimulated with pIC. However, it suggests that the differences in response to pIC between fish held at 10 vs. $16^{\circ} \mathrm{C}$ were not caused by an enhanced sensitivity to double-stranded RNA due to an overexpression of TLR3 in the spleens of fish held at $16^{\circ} \mathrm{C}$ and injected with pIC. The results of Rodriguez et al. [42] for in vivo stimulation of rainbow trout with IP injection of pIC also agree with ours, as these authors detected no significant induction of TLR3 mRNA following injection of this viral mimic. Interestingly, these authors and others [43] have shown up to $~ 30$-fold induction of TLR3 transcripts by pIC in isolated rainbow trout cells/cell culture, and this is similar to what has been observed in mammalian macrophages [44].

In the current study, TLR9 transcripts were found by both the microarray and QPCR analyses to be significantly up-regulated by $\mathrm{pIC}$ at $6 \mathrm{HPI}$ in $16^{\circ} \mathrm{C}$ fish, and at $24 \mathrm{HPI}$ for fish held at $10^{\circ} \mathrm{C}$ (Table 2; Figure $8 \mathrm{~B}$ ); the QPCR analysis showed that mRNA levels of TLR9 were significantly different between 10 and $16^{\circ} \mathrm{C}$ pIC injected fish sampled at 6HPI (Figure $8 \mathrm{~B}$ ). Like in mammals, the main ligand of TLR9 in fish is thought to be viral/bacterial unmethylated CpG DNA [41,45]. It is unclear what the roles of TLR9 during the host response to viral dsRNA could be, but it is apparent that temperature can also have an impact on the responses of fish to other pathogens such as bacteria by modulating TLR9 mRNA expression [41]. Further research is warranted to elucidate the modulations of TLRs by antigens and/or changes in the environment in teleost fish.

Other important sensors of viruses are cytosolic PRRs, such as the RIG-I like receptors (RLRs) and the dsRNA activated protein kinase (PKR). DHX58 (alias LGP2) is a RLR that was found to be highly induced at the mRNA level by pIC compared to PBS at both $10^{\circ} \mathrm{C}$ and $16^{\circ} \mathrm{C}$ and also differentially expressed (at FDR $=1 \%$ ) between fish injected with $\mathrm{pIC}$ at 10 and $16^{\circ} \mathrm{C}$ at both time points in the QPCR and microarray experiments (Tables 1 and 2, Figure 8D). Previous studies have reported up-regulation of DHX58 mRNA by pIC in both cod spleen and brain $[22,25]$. In addition, QPCR was used to show that DHX58 mRNA was significantly up-regulated in the brains [25], 

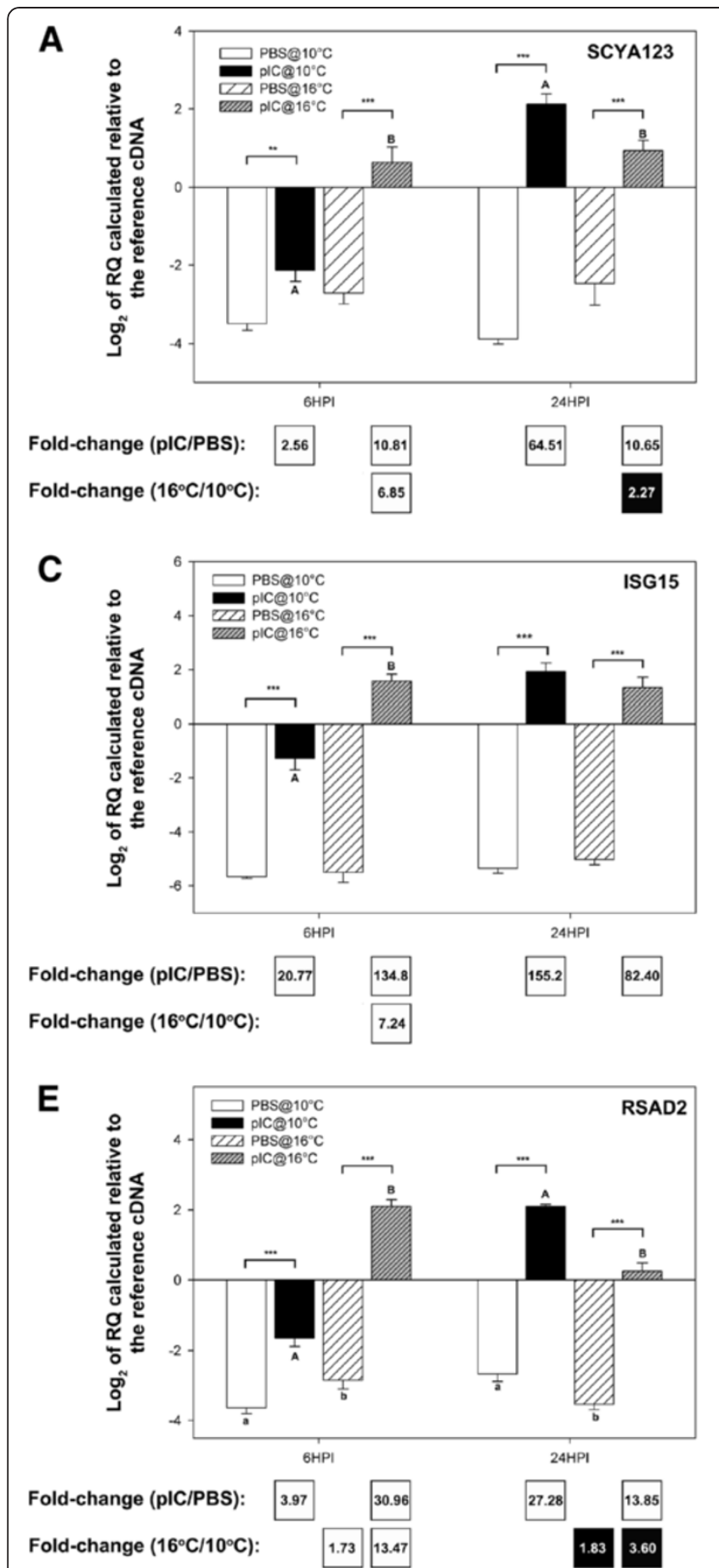

B

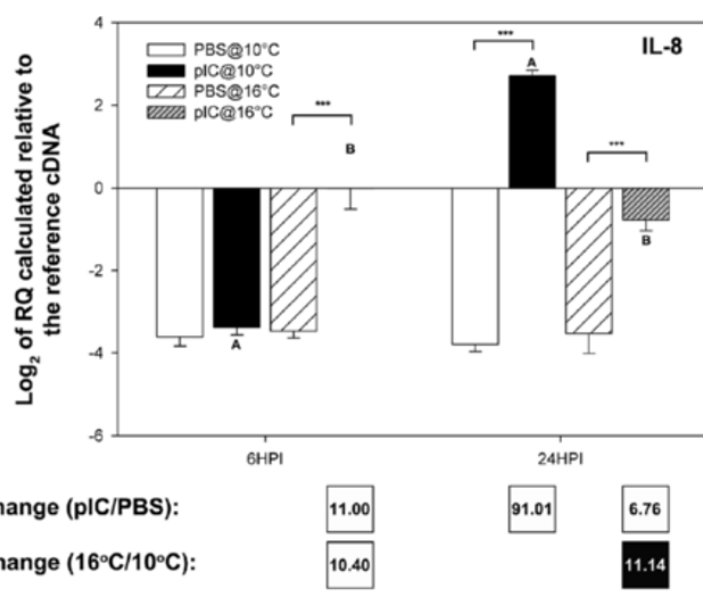

D

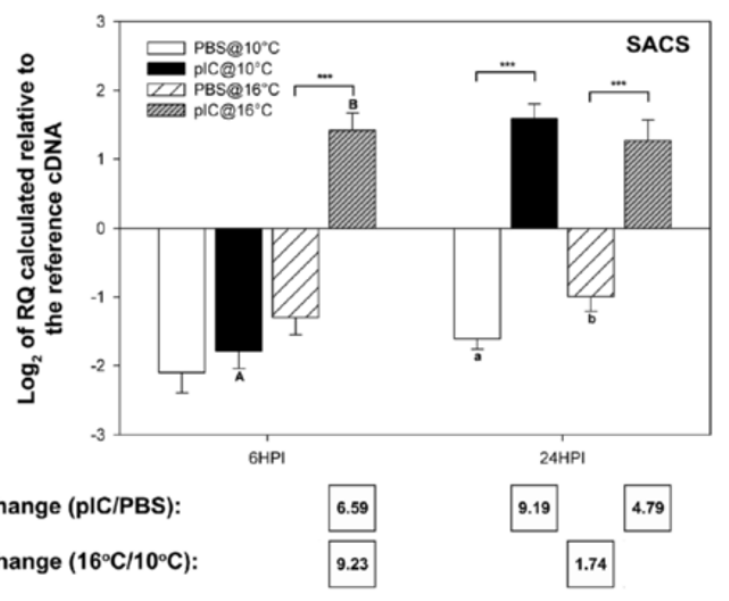

Figure 10 QPCR results for transcripts with putative roles as immune effectors (see Additional file 2: Figure S1 schema of the TLR/ interferon pathways). Data is presented as mean $\log _{2}$ transformed data \pm SE. Different letters represent significant differences between fish injected with pIC at different temperatures within each time point. An asterisk $\left(^{*}\right)$ represents a difference between a given pIC-injected group and the time- and temperature-matched PBS-injected group ( $\left.{ }^{*} p<0.05 ;{ }^{* *} p<0.01 ;{ }^{* * *} p<0.001\right)$. Fold-changes in white boxes are always plC/PBS or $16^{\circ} \mathrm{C} / 10^{\circ} \mathrm{C}$ and are shown in the boxes underneath each panel. Only significant differences are shown. Black boxes show $1 /$ fold-change for comparisons that yielded values less than one (for more details on fold-change calculations, refer to the methods section). A) SCYA123; B) IL-8; C) ISG15; D) SACS; E) RSAD2. 
but not the spleens [22], of asymptomatic high nodavirus carrier Atlantic cod. As in Rise et al. [22,25] we detected peak up-regulation of DHX58 mRNA at 24HPI for fish injected with pIC at $10^{\circ} \mathrm{C}$. In the spleens of fish injected with $\mathrm{pIC}$ at $16^{\circ} \mathrm{C}$, the fold up-regulation (compared to the PBS control) of DHX58 transcript was similar at 6HPI and 24HPI (13-fold and 12-fold, respectively) (Figure 8D). The roles of DHX58 in the anti-viral response are still unclear $[22,46,47]$. However, there is some experimental evidence that it may induce or repress RIG-I/MDA5 dependent signal transduction in a virus-dependent manner [46]. Thus, it is still not clear what impacts the observed temperaturedependent modulation of DHX58 response to pIC could have in the anti-viral immunity of cod. We observed similar differences in the expression of PKR mRNA (Figure 8C). Like TLR9, DHX58, STAT1, Deltex3, ZNFX1, IL-8 and SACS, PKR did not respond to pIC at 6HPI in fish held at $10^{\circ} \mathrm{C}$, but it was significantly up-regulated at the same time point in the spleens of fish held at $16^{\circ} \mathrm{C}$ and injected with pIC. In mammals, the main anti-viral function of PKR was originally thought to be the phosphorylation of eIF2 $\alpha$, leading to reduced protein synthesis [48]. More recently, it has been demonstrated that PKR has roles in modulating apoptosis via NF- $\mathrm{kB}$ and the growthinhibitory activity of IRF1 [49]. Therefore the observed influence of pIC, temperature and time on PKR mRNA expression could impact the fish's ability to fight a viral infection.

\section{Genes with putative roles in signal transduction and transcription regulation}

In mammals, downstream signaling of TLRs and RLRs involves activation of NF- $\mathrm{KB}$ transcription factors [46,50]. There is some evidence of a similar mechanism in fish, since expression constructs containing a constitutively active form of the zebrafish (Danio rerio) TLR3 transfected into ZFL cells induced NF- $\mathrm{kB}$ mediated luciferase fluorescence [38]. An important step in TLR signaling in mammals is the activation of the Inhibitor of NF- $\mathrm{kB}$ Kinases (IKKs), which in turn phosphorylate the Inhibitor of NF$\kappa B$ proteins (ІкBs). Phosphorylation targets IкBs for degradation, and in their absence, the NF- $\mathrm{kB}$ proteins accumulate in the nucleus and regulate mRNA transcription [51,52]. In higher vertebrates, ІкB $\alpha$ is thought to regulate transient activation of NF- $\mathrm{kB}$. As such it is rapidly degraded in response to stressful stimuli, but then quickly re-synthesized due to the presence of an NF-kB response element in its promoter region [51] (see Additional file 2: Figure $\mathrm{S} 1$ for a putative equivalent Atlantic cod pathway). At 6HPI, both the microarray and the QPCR studies showed an significant up-regulation of ІкB $\alpha$ mRNA by pIC at both temperatures (Table 1 and Figure 9A). This may be an indication of the process of re-synthesis of this protein in the spleen cells following pIC stimulation.
However, the QPCR-detected up-regulation of $\mathrm{IkB} \alpha$ mRNA by pIC at $6 \mathrm{HPI}$ was higher in fish held at $10^{\circ} \mathrm{C}$ than in fish held at $16^{\circ} \mathrm{C}$ (3.82-fold vs. 1.94-fold, respectively). Moreover, the difference in mRNA expression of I $\mathrm{B} \alpha$ between $10^{\circ} \mathrm{C}$ and $16^{\circ} \mathrm{C}$ fish injected with pIC at 6HPI was also significant (both in the QPCR and the microarray studies). It is possible that the early response of IFN pathway genes observed in the fish held at $16^{\circ} \mathrm{C}$ (see Figure $5 \mathrm{~B}$ and 7) was in part due to a reduced resynthesis of IкB $\alpha$, leading to a more pronounced NF- $\kappa B-$ mediated induction of transcription. At 24HPI we detected no significant differences in the mRNA expression of IкB $\alpha$ in fish held at $10^{\circ} \mathrm{C}$ or $16^{\circ} \mathrm{C}$ with either the microarray (Table 2) or QPCR (Figure 9A) studies. The microarray analysis indicated that IKK $\alpha$ was significantly up-regulated by pIC at this point only in the spleens of fish held at $10^{\circ} \mathrm{C}$ (Table 2). Since IKKs are also essential to NF- $k B$ activation, this difference may have contributed to the differences in immune-related gene expression observed at 24HPI (e.g. as shown by the hierarchical clustering; Figures 5, 6 and 7). Collectively, our results suggest that, as in higher vertebrates, timing and intensity of Atlantic cod immune responses are partly regulated by NF$\kappa B$ transcription factors [51].

The interferon regulatory factor (IRF) genes are also key to the activation of the IFN pathway [53]. In this work all 3 IRFs (i.e. IRF1, IRF7 and IRF10) that had been previously identified as pIC-responsive in cod [22] were shown to be up-regulated in spleen by this viral mimic (Table 1 and 2, Figure $9 \mathrm{~B}, \mathrm{C}$ and $\mathrm{D}$ ). Moreover, all studied IRFs presented the same overall expression profile as most IFN pathway-related genes identified in this study. This profile is characterized by a higher expression at 6HPI in fish injected with pIC and held at $16^{\circ} \mathrm{C}$ vs. $10^{\circ} \mathrm{C}$, but greater expression in this latter group at 24HPI. In higher vertebrates both IRF1 and IRF7 have been implicated as positive modulators of the type I IFN response to viruses, with IRF7 being essential for interferon-related gene expression [53]. Furthermore, in the current microarray experiment TANK-binding kinase 1 (TBK1), which activates IRF7 by phosphorylation, was found to be more highly expressed in the spleens of fish injected with pIC at $10^{\circ} \mathrm{C}$ and sampled at 24HPI (1.37 fold - Table 2) than in the spleens of fish injected with $\mathrm{pIC}$ at $16^{\circ} \mathrm{C}$ at this time point. It is likely that the differential upregulation of the IRFs and TBK1 in fish stimulated with $\mathrm{pIC}$ at the different temperatures contributed to the global expression profiles (i.e. with several IFNrelated genes peaking at different times in fish injected with pIC at $10^{\circ} \mathrm{C}$ as compared to those injected with pIC at $16^{\circ} \mathrm{C}$ ) depicted in Figures 5, 6 and 7.

Once type I interferons (e.g. IFN- $\beta$ ) are expressed, they interact with specific cell surface receptors (IFN $\alpha / \beta$ 
receptors [IFNAR]) triggering the expression of IFN stimulated genes (ISGs) [54]. This signaling cascade occurs partly through the dimerization of the signal transducer and activator of transcription (STAT) 1 and 2 proteins and their interaction with IRF9. The STAT1/STAT2/ IRF9 complex then further induces STAT1 expression [54]. In cod, STAT1 mRNA was previously identified as being significantly more highly expressed in the brains of fish with a high nodavirus carrier status compared to fish with no/low nodavirus; STAT1 mRNA was also shown to be significantly up-regulated in cod brain 24 and $72 \mathrm{~h}$ after IP injection with pIC [25]. In the current study we found that: 1) at 6HPI STAT1 was only upregulated in fish injected with $\mathrm{pIC}$ at $16^{\circ} \mathrm{C} ; 2$ ) as with the IRFs at 24HPI, both pIC-injected groups showed significant STAT1 mRNA up-regulation; and 3) the STAT1 QPCR-detected up-regulation was more pronounced in the $10^{\circ} \mathrm{C}$ pIC-injected fish and sampled at 24HPI (5.49fold at $10^{\circ} \mathrm{C}$ vs. 2.91 -fold at $16^{\circ} \mathrm{C}$ ) (Figure 9E). This suggests that the modulation of the expression of IRFs at the mRNA level could have affected the production of type I IFN, and together with the observed STAT1 transcript expression profiles may also have contributed to the global gene expression profiles depicted in Figures 5, 6 and 7.

\section{Genes with putative functions as immune effectors}

The shift in the timing of the transcriptome response to $\mathrm{pIC}$ between fish stimulated at $10^{\circ} \mathrm{C}$ vs. $16^{\circ} \mathrm{C}$ (Figures 5, 6 and 7) was also observed for several immune effector genes (Figure 10A-E). Of the genes studied with QPCR, IL-8 transcript expression is known to be under the control of NF- $\mathrm{BB}$ in mammals as evidenced by marked reductions in its expression in $\mathrm{IKKe}^{-/-}$mouse cells [55] (See Additional file 2: Figure S1 for a putative Atlantic cod NF- $\mathrm{KB}$ dependent control of immune effector gene transcription). In the present work, IL-8 transcript was 11 -fold significantly more highly expressed in the spleens of pIC injected fish held at $16^{\circ} \mathrm{C}$ and sampled at 6HPI compared with $16^{\circ} \mathrm{C}$ PBS controls. Further, at $24 \mathrm{HPI}$, IL-8 mRNA was 91-fold up-regulated in the spleens of pIC-injected fish held at $10^{\circ} \mathrm{C}$, but only $\sim 7$-fold up-regulated in the spleens of pIC-injected fish held at $16^{\circ} \mathrm{C}$, compared with the time- and temperature-matched PBS controls (Figure 10B). Two of the genes identified in the microarray study and subjected to QPCR validation are known ISGs: ISG15 and RSAD2 (alias viperin) [56]. These genes were previously reported to be pICresponsive in the cod spleen [22] and significantly upregulated in the brains of cod by asymptomatic high nodavirus carrier state and IP pIC treatment [25]. It is not surprising that, in the current study, these genes presented the same mRNA expression profiles as the IRFs (Figure 10C and E). For example, ISG15 was $\sim 7$ fold significantly more highly expressed in $16^{\circ} \mathrm{C}$ pIC injected fish at $6 \mathrm{HPI}$ and 1.51 fold more highly expressed in $10^{\circ} \mathrm{C}$ pIC-injected fish sampled at $24 \mathrm{HPI}$ when compared to the respective time-matched pIC injected fish (Note: This difference was detected in the QPCR experiment but was only significant in the microarray experiment, possibly due to the fact that our ISG15 QPCR primers only amplified 2 of the 3 known ISG15 paralogs [57]). Further, RSAD2 mRNA was 13.5-fold significantly more highly expressed in $16^{\circ} \mathrm{C}$ pIC-injected fish at $6 \mathrm{HPI}$ compared to $10^{\circ} \mathrm{C}$ pICinjected cod at $6 \mathrm{HPI}$ and 3.6 fold significantly more highly expressed in $10^{\circ} \mathrm{C}$ pIC-injected fish at 24HPI compared to $16^{\circ} \mathrm{C}$ pIC-injected fish at the same time point. However, unlike what was observed for IL-8, the peak fold-change in pIC-stimulated fish for ISG15 and RSAD2 mRNA expression (compared with the timeand temperature-matched PBS controls) was similar for $16^{\circ} \mathrm{C}$ fish at $6 \mathrm{HPI}$ as compared with $10^{\circ} \mathrm{C} \operatorname{cod}$ at 24 HPI (Figure 10C and E).

SCYA123 [22] and SACS [25] have both been previously identified as up-regulated by $\mathrm{pIC}$ in cod, and as expected both SCYA123 and SACS were significantly up-regulated in the spleen of cod injected with $\mathrm{pIC}$ at 10 and $16^{\circ} \mathrm{C}$ (Figure $10 \mathrm{~A}$ and $\mathrm{D}$ ). However, little is known about the roles of these proteins in the anti-viral response. SCYA123 is a small inducible cytokine, but phylogenetic clustering indicates that it is most related to the CCL19 group [58] of higher vertebrates. In mammals, the CCL19 chemokines are constitutively expressed and thought to have a minor role in immunity (see [58] and references therein). Nonetheless, it is clear that SCYA123 transcripts are up-regulated by pIC and other antigens (e.g. formalin-killed atypical Aeromonas salmonicida) in the spleen of cod [21-23,58], and therefore, at least in this species, have some role in finfish immunity. Mutations in the SACS gene lead to the human disease spastic ataxia of Charlevoix-Saguenay [59], and it is known that the very large sacsin protein (4579 amino acid residues) encoded by SACS possesses heat shock protein (HSP)-like ATPase domains and HSP-like activity [60]. However, the function of this gene in immunity remains unclear [25]. SACS mRNA was shown by QPCR to be up-regulated by asymptomatic high nodavirus carrier state and IP pIC treatment in brains of cod [25] and by ISA (Infectious Salmon Anemia) virus infection in salmonid TO cells [20]. Moreover, SCYA123 and SACS presented mRNA expression profiles similar to other known immune-related genes reported here (Figures 5, 6 and 7). Interestingly, the transcript expression profiles of SCYA123 and SACS at 6HPI were more similar to those of IL-8 and RSAD2 but at 24HPI was more similar to that of ISG15. Therefore, it is possible that these genes share some of their regulatory mechanisms, and they 
likely play important roles in Atlantic cod responses to viruses.

\section{Cellular response to stress and innate immunity}

The mild increase in temperature alone did not cause up-regulation of the genes considered to be part of the conserved cellular stress response (e.g. HSP40, HSP70 and peptidyl-prolyl-isomerase [61]). In contrast, several chaperone-like genes were more highly expressed at 24HPI in the fish injected with pIC at $16^{\circ} \mathrm{C}$ compared to fish injected with $\mathrm{pIC}$ at $10^{\circ} \mathrm{C}$. In fact, at this time point $2 \mathrm{GO}$ terms related to protein folding (protein folding and unfolded protein binding) were significantly enriched in the list of genes up-regulated by $\mathrm{pIC}$ at $16^{\circ} \mathrm{C}$ when compared to the list of genes up-regulated by pIC at $10^{\circ} \mathrm{C}$. In the microarray experiment, chaperone-like genes such as HSP90-alpha, HSP90-beta, HSC71, HSP47, peptidyl-prolylisomerase A, CCT1 and CCT6 (Table 2) were identified as either being induced by pIC at 24HPI in fish injected at $16^{\circ}$ $\mathrm{C}$ but not in fish injected at $10^{\circ} \mathrm{C}$, or significantly more highly expressed at the mRNA level in the pIC@ $16^{\circ} \mathrm{C}$ fish at 24HPI when compared to the pIC@10 $\mathrm{C}$ (Table 2). Many of these genes (e.g. HSP90-alpha, HSP47 and CCT1) were previously identified as heat shock-responsive in the cod liver [24] and in a multiple-tissue RNA-seq study in rainbow trout [35]. This suggests that even though heat alone did not elicit a robust cellular stress response, the combination of heat and pIC injection did induce molecular biomarkers of cellular stress.

There is evidence from the mammalian literature that HSPs play a key role in modulating the innate immune response [62]. Interestingly at 24HPI, the GO terms "regulation of interferon-gamma-mediated-signaling", "regulation of signaling process", "regulation of signal transduction", and "regulation of cytokine-mediated signaling pathway" were significantly over-represented in the list of genes up-regulated by pIC at $16^{\circ} \mathrm{C}$ compared to those up-regulated by $\mathrm{pIC}$ at $10^{\circ} \mathrm{C}$. These $\mathrm{GO}$ terms were largely associated with probes representing HSP90like transcripts or HSP70. It is known that, at least in higher vertebrates, the cellular response to stress prevents innate immune signaling [62], and these effects are to some extent mediated by HSPs. It is possible that the significantly reduced magnitude of induction by pIC observed for some immune-relevant genes (e.g. DHX58, STAT1, SCYA123, IL-8) in Atlantic cod held at $16^{\circ} \mathrm{C}$ and sampled at 24HPI compared with pIC-injected fish held at $10^{\circ} \mathrm{C}$ and sampled at 24HPI may have been a result of the activation of the cellular stress response in these animals prior to the 24HPI time point.

\section{Conclusions}

In this study we used microarrays, followed by QPCR, to investigate the interaction between a moderate temperature increase and the innate immune response of cod after pIC stimulation. This is the first time, to our knowledge, that the global gene expression analysis has been used to investigate the interaction between changes in environmental conditions and the antiviral immune response of this commercially important species. We have been able to demonstrate that a moderate increase in seawater temperature, similar to those experienced by farmed Atlantic cod in sea-cages in Newfoundland during the summer, causes a massive shift in the spleen transcriptome response to a viral mimic. Furthermore, we present evidence to suggest that these changes may be, in part, regulated by changes in signal transduction (particularly in the NF- $\mathrm{KB}$ and IFN pathways) and by interactions between the cellular stress response and the innate immune response. Collectively, this new information enhances our understanding of the interactions between temperature and the Atlantic cod immune system, and will be valuable in global efforts to improve cod aquaculture practices and broodstock.

\section{Methods}

All experimental procedures were conducted with approval of Memorial University's Institutional Animal Care Committee, and followed the guidelines of the Canadian Council on Animal Care.

\section{Experimental animals}

Passive integrated transponder (PIT)-tagged Atlantic cod belonging to 10 different families ( 30 fish per family) from the Atlantic Cod Genomics and Broodstock Development Project (CGP) year-class 3 (YC3) $(52.6 \pm 2.5 \mathrm{~g})$ were obtained from the Huntsman Marine Science Centre in St. Andrew's, New Brunswick. The fish were transported to the Ocean Sciences Centre of Memorial University of Newfoundland in October of 2008, and placed in a $3000 \mathrm{l}$ tank supplied with flow-through seawater (at $10^{\circ} \mathrm{C}$ and $>90 \%$ oxygen saturation). After one month of acclimation, the fish were distributed amongst eight $500 \mathrm{l}$ tanks ( 36 fish per tank) (Figure 1A), each with approximately equal numbers of fish from each family in each tank. Fish were fed to apparent satiation throughout the acclimation period.

\section{Experimental design}

Figure 1 provides an overview of the complete experimental design. Four tanks out of the 8 were randomly assigned as temperature control tanks (i.e. kept at $10^{\circ} \mathrm{C}$ for the entire duration of the experiment), while the remaining 4 tanks were assigned as heat-exposed (Figure 1A). After the fish were allowed to acclimate to the $500 \mathrm{l}$ tanks for 2 weeks (Figure 1B), 3 fish from each tank ( $\mathrm{N}=12$ per group) had their blood sampled for the determination of plasma cortisol levels. These groups were designated "control before temperature 
increase" (CBTI) and "heat-exposed before temperature increase" (HBTI). Thereafter, water temperature in the heat-exposed tanks was increased by $1^{\circ} \mathrm{C}$ every $\sim 5$ days. These tanks reached $16^{\circ} \mathrm{C}$ after approximately 1 month, and were held for another $\sim 1$ week at that temperature (Figure 1C). Fish were fed to apparent satiation during this $\sim 5$ week period and no significant differences in food consumption were detected between groups (data not shown). At this point, 8 fish per tank were sampled for plasma cortisol, 2 fish per tank had their spleens removed for subsequent microarray and QPCR analyses, and the remaining fish were given an IP injection of either polyriboinosinic polyribocytidylic acid (pIC) (Sigma Co, St. Louis, MO) $\left[2 \mu \mathrm{g}\right.$ of $\mathrm{pIC} \mathrm{g}^{-1}$ wet mass, $0.5 \mu \mathrm{g} \mu \mathrm{l}^{-1}$ in ice-cold $0.2 \mu \mathrm{m}$-filtered phosphate buffered saline (PBS)] or an equivalent volume of ice-cold $0.2 \mu \mathrm{m}$ filtered PBS after recording their PIT tag ID (Figure 1D). The fish sampled prior to $\mathrm{pIC}$ injection were designated as "control before injection" (CBI) and "heat-exposed before injection" (HBI). Finally, at both temperatures (10 and $16^{\circ}$ C), 5 fish from each of two tanks $(\mathrm{N}=10$ per group / temperature) were sampled at 6 hours post-injection (6HPI) and at 24HPI (Figure 1E) to examine the impact of elevated rearing temperature on the spleen's transcriptome response to the viral mimic pIC.

\section{Immune stimulation}

Prior to immune stimulation, fish were starved for 24 hours and feeding was not resumed thereafter. After being lightly anesthetized using a non-lethal dose (100 $\mathrm{mg} \mathrm{l}^{-1}$ ) of tricaine-methane-sulphonate (TMS) (Syndel Laboratories, Qualicum Beach, BC), equal numbers of fish were injected with pIC or PBS. Thereafter, they were allowed to recover (i.e. re-establish normal swimming behavior) in a "recovery-tank" filled with seawater from the same system and temperature as before injection, and then returned to their original tanks. Oxygen levels in the recovery tanks were constantly monitored and maintained above $90 \%$ of air saturation.

\section{Tissue and blood sampling}

At all sampling points, the fish were quickly netted from their tanks and placed in an anaesthetic bath containing a lethal dose of TMS (400 $\mathrm{mg} \mathrm{l}^{-1}$ ). For cortisol analysis, whole blood was quickly obtained from the caudal vein using heparinized (100 $\mathrm{U}$ of sodium heparin $\mathrm{ml}^{-1}$ ) $1 \mathrm{ml}$ syringes (BD Medical Supplies, Franklin Lakes, NJ), centrifuged at $5000 \times \mathrm{g}$ for 10 minutes $\left(4^{\circ} \mathrm{C}\right)$, and the resulting plasma was placed in separate $1.5 \mathrm{ml}$ microcentrifuge tubes and frozen in liquid nitrogen. Spleen samples were collected using standard aseptic molecular biology techniques, placed in certified RNase-free $1.5 \mathrm{ml}$ microcentrifuge tubes and flash-frozen in liquid nitrogen. All spleen samples were stored at $-80^{\circ} \mathrm{C}$ until RNA isolations were performed.

Twelve fish (3 per tank) were sampled for plasma cortisol before the temperature increase (BTI), and compared with values before injection (BI), to allow us to determine the degree of stress induced by the increasing temperature regimen and being held at $16^{\circ} \mathrm{C}$ for 1 week. Thirty-two fish were sampled prior to the pIC and PBS injections (BI) to allow for correlation analysis of the relationship between temperature-induced plasma cortisol levels and constitutive (pre-injection) spleen immune-related gene expression using QPCR. However, because holding the fish at 10 vs. $16^{\circ} \mathrm{C}$ only resulted in 6 genes being differentially expressed (see results), this analysis was never performed.

\section{Plasma cortisol assay}

An enzyme-linked immunosorbent assay (ELISA) kit (Neogen, Lexington, KY) was used to measure plasma cortisol levels, and the methods are described in detail elsewhere [24]. The cortisol data was subjected to a Kolmogorov-Smirnov normality test, and a two-way ANOVA (with temperature and time point as main effects). However, neither of these factors had a significant impact on cortisol data, and thus, no further statistical analyses were carried out.

\section{RNA extractions, DNase-I treatment and column purification}

RNA extractions, DNase-I treatment and column purification were performed using the TRIzol reagent (Invitrogen, Carlsbad, CA), RNase-free DNase Set (Qiagen, Valencia, CA) and RNeasy MinElute Clean-up Kit (Qiagen), respectively. All procedures were done according to the manufacturers' instructions with minor changes as described in Hori et al. [24].

\section{Microarray hybridizations}

A schema of the microarray experimental design is presented in Figure 2. In summary, 6 individuals from each of the following groups were used for microarray analysis: CBI; HBI; pIC 6HPI@10 ${ }^{\circ} \mathrm{C}$; PBS 6HPI@10 $\mathrm{C}$; pIC 6HPI@16 ${ }^{\circ} \mathrm{C}$; PBS 6HPI@16 ${ }^{\circ} \mathrm{C}$; pIC 24HPI@10 $\mathrm{C}$; PBS $24 \mathrm{HPI} 10^{\circ} \mathrm{C}$; pIC $24 \mathrm{HPI} 16^{\circ} \mathrm{C}$; PBS 24HPI@16 $\mathrm{C}$. In these abbreviations, the “@” followed by a number indicates the temperature at which fish were held, pIC refers to fish immune-stimulated with the viral mimic pIC, PBS refers to sham-injected fish and HPI stands for "hours post-injection".

For all of the above groups, 3 individuals from each of 2 different replicate tanks $(\mathrm{N}=6)$ were selected based on RNA quantity and quality for microarray analysis. Seven $\mu \mathrm{g}$ of spleen DNase I-treated and columnpurified total RNA from individuals involved in 
immune stimulation experiment that included pIC and formalin-killed Aeromonas salmonicida injections were pooled to generate a "common reference" sample. The resulting "common reference" pool included all of the individuals used in the present microarray experiment. After pooling, the common reference quantity was measured using spectrophotometry and its quality was checked by $1 \%$ agarose gel electrophoresis. For each experimental sample (e.g. pIC 6HPI@ $10^{\circ} \mathrm{C}$, individual 1) or the common reference, $5 \mu \mathrm{g}$ of DNase I-treated, column-purified RNA were used for target synthesis. Complementary DNA (cDNA) synthesis and labeling were performed using Invitrogen's SuperScript Direct Labeling kit following the manufacturer's instructions. The experimental sample was always labeled with ALEXA 647 fluorophore and the common reference was always labeled with ALEXA 555 fluorophore (Figure 2). Labeled cDNA from one experimental sample and the common reference were pooled together and hybridizations were performed at $42^{\circ} \mathrm{C}$ for $\sim 16$ hours as described in Booman et al. [21]. Detailed protocols on all hybridizations and washing are available in Booman et al. [21].

\section{Microarray data acquisition and pre-processing}

Microarrays were scanned at $5 \mu \mathrm{m}$ using a ScanArray Gx Plus scanner and ScanExpress software v4.0 (Perkin Elmer, Woodbridge, ON) with photomultiplier tube (PMT) settings adjusted for each channel of each array and laser power set at 90\%. For each channel (i.e. ALEXA 647 or 555) on a given array, the average signal was measured in a circle of diameter $\sim 2000$ pixels. PMT settings were adjusted in subsequent scans until the average signal was between 600 and 1000 signal units and there was no more than 200 signal units difference between channels. Raw microarray data was saved as TIFF images and probe intensities were extracted using Imagene v7.5 (BioDiscovery, El Segundo, CA). In R, flagged and control spots were removed and the mArray package of Bioconductor was used to $\log _{2}$ transform and Loess normalize the data by sub-grid (i.e. print-tip Loess). Thresholding and averaging of the probes were performed as described in Booman et al. [21]. The R scripts are described in full in the supplemental materials of Booman et al. [21]. This microarray dataset is described in the Gene Expression Omnibus (GEO) series GSE27299, and individual samples are available under GEO accession numbers GSM675013GSM675072 (including both pre- and post-normalization data).

\section{Microarray data analysis}

The Significance Analysis of Microarrays (SAM) algorithm [31] was used to perform two-class comparisons between groups (e.g. pIC 6HPI@10 $10^{\circ} \mathrm{C}$ v. pIC 6HPI@16 ${ }^{\circ} \mathrm{C}$ ) in order to identify differentially expressed genes (at $\mathrm{FDR}=1 \%$ ). Prior to SAM analysis, all probes that were absent in more the $25 \%$ of the arrays in the totality of the experiment (i.e. 15 or more out of 60 arrays) were removed from the dataset. This procedure generated a final dataset containing 12,154 probes. Any remaining missing values were imputed using the EM_array method from the LSimpute algorithm $[63,64]$. We used the Bioconductor implementation of SAM available in the siggenes package [65] and set our False Discovery Rate (FDR) threshold to $1 \%$ to generate gene lists. Detailed R scripts are available in the supplemental materials of Booman et al. [21]. Resulting data was then clustered in Genesis [66] using Pearson uncentered correlation and complete linkage hierarchical clustering.

Resulting gene lists were re-annotated using the expressed sequence tags (ESTs) or contiguous sequences (contigs) from which 50 mer oligonucleotide probes on the array were designed. For details on probe design please refer to Booman et al. [21]. Automated BLASTx alignment of these sequences against the NCBI nr database was performed using the Blast2GO tool [67] with thresholds set as follows: E-value $<10^{-5}$, maximum number of hits $=100$ and high scoring pairs (HSP) $>33$. BLASTx results for each probe were mapped to Gene Ontology (GO) terms using Blast2GO. For detailed information on how BLASTx results are mapped to GO terms, please refer to the Blast2GO manual and Conesa et al. [67]. Biological process GO mapping results for the genes differentially expressed between fish injected with $\mathrm{pIC}$ at the different temperatures (i.e. 10 vs. $16^{\circ} \mathrm{C}$ ) were normalized to GO term hierarchy level 2 and plotted as pie charts (Figure 3 A-D). GO term enrichment analysis was performed to compare the pIC response at different temperatures using Fisher's exact test as implemented by GOSSIP in the Blast2GO software with a p-value cutoff of $<0.01$. We compared the distribution of GO terms between lists of genes differentially expressed in the spleens of fish injected with pIC to those injected with PBS at the different temperatures [e.g. (genes upregulated in pIC injected fish $@ 10^{\circ} \mathrm{C}$ vs. time-matched PBS injected controls @ $10^{\circ} \mathrm{C}$ ) compared to (genes upregulated in pIC injected fish $@ 16^{\circ} \mathrm{C}$ vs. time-matched PBS-injected controls @16 ${ }^{\circ} \mathrm{C}$ )].

\section{QPCR analysis}

From the informative gene lists that were generated using SAM analysis, the following 4 genes of interest (GOI) were selected for QPCR analysis based on their known transcript expression responses in fish exposed to viruses or viral mimics [20,22,25]: TLR9 (Toll-like receptor 9), PKR (double-stranded RNA activated protein kinase), IRAK4 (interleukin-1 receptor-associated kinase 4), and IкB $\alpha$ (NF-кB inhibitor alpha). The following 13 
Table 3 QPCR Primers

\begin{tabular}{|c|c|c|c|c|c|}
\hline Gene & & Primer sequence $5^{\prime}$ to $3^{\prime}$ & Amplification Efficiency (\%) & $\mathrm{R}^{2}$ & Amplicon Size (bp) \\
\hline \multirow[t]{2}{*}{ Deltex3 ${ }^{b}$} & Forward & TCCACCACAAGACCAGCATCA & 98.5 & 0.99 & 110 \\
\hline & Reverse & ACTTCACTCGATGCCTITCGC & & & \\
\hline \multirow[t]{2}{*}{$\mathrm{DH} \times 58^{\mathrm{c}}$} & Forward & ACAGAAGCCATCGCAGAAAT & 92.9 & 0.99 & 105 \\
\hline & Reverse & TITGCAGCACGAATCAAAC & & & \\
\hline \multirow[t]{2}{*}{$\mid \mathrm{kBa} a^{\mathrm{C}}$} & Forward & GCCAGCAACTGATAAAGCATC & 92.1 & 0.99 & 132 \\
\hline & Reverse & GGTCACAGAGGGAGACAGAAAA & & & \\
\hline \multirow[t]{2}{*}{$\| L-8^{c}$} & Forward & GTGTTTCCAGCAGATCACTCG & 94.9 & 0.99 & 118 \\
\hline & Reverse & TGTTCCACTTGGTGAGGAGTC & & & \\
\hline \multirow[t]{2}{*}{ IRAK4 ${ }^{\mathrm{C}}$} & Forward & CGTGGATTACAAGATGGATAAGC & 95.8 & 0.99 & 102 \\
\hline & Reverse & TCGTCGGGGTCTAAAAAGTC & & & \\
\hline \multirow[t]{2}{*}{$\mid \mathrm{RF} 1^{\mathrm{a}}$} & Forward & AGAAGGACGCCAGTCTGTTCAA & 88.5 & 0.99 & 100 \\
\hline & Reverse & GCGGAAGTTGGCTTTCCATT & & & \\
\hline \multirow[t]{2}{*}{$\mathrm{IRF}^{\mathrm{a}}$} & Forward & GGTCGTCGGAGTTCTTGGAGTT & 95.1 & 0.99 & 102 \\
\hline & Reverse & CCAAACGACAAGGCCAAATG & & & \\
\hline \multirow[t]{2}{*}{$\operatorname{IRF} 10^{\mathrm{a}}$} & Forward & CGAGGCGGTAGACCTTGTAG & 104.6 & 0.94 & 161 \\
\hline & Reverse & GGGCAGGTACAAAGGGAAAT & & & \\
\hline \multirow[t]{2}{*}{$1 S G 15^{c}$} & Forward & AGGACCAACAAAGGCTGATG & 94.7 & 0.99 & 110 \\
\hline & Reverse & CAGCCGTCCGTTAAGGTAGA & & & \\
\hline \multirow[t]{2}{*}{$\mathrm{PKR}^{\mathrm{C}}$} & Forward & ATTGCATCAGGTTCCCAATC & 94.4 & 0.99 & 174 \\
\hline & Reverse & GCCGTTACCAGACCAAAATC & & & \\
\hline \multirow[t]{2}{*}{$\mathrm{RSAD}^{\mathrm{c}}$} & Forward & TGTITCCACACAGCGAAGAC & 95.8 & 0.99 & 108 \\
\hline & Reverse & TCCGCCAGAGAAGTTGATCT & & & \\
\hline \multirow[t]{2}{*}{ SACS $^{b}$} & Forward & СTCCCACTGCCAATGTCATTC & 88.5 & 0.99 & 102 \\
\hline & Reverse & TCAAGAAAACGTCCCAAGGC & & & \\
\hline \multirow[t]{2}{*}{ SCYA $123^{C}$} & Forward & GCTCTGGGTCGTGTACCTCT & 94.1 & 1.00 & 189 \\
\hline & Reverse & TCTCTCTGGACGAACAAGCA & & & \\
\hline \multirow[t]{2}{*}{ STAT1 ${ }^{\mathrm{b}}$} & Forward & GCCAATGCCATGTGTTATG & 97.5 & 0.99 & 100 \\
\hline & Reverse & ACCTGGAGCAGTTCGTCAGT & & & \\
\hline \multirow[t]{2}{*}{$\operatorname{TLR3}^{\mathrm{C}}$} & Forward & CCTGAAACGCAACTCTATCTCC & 90.6 & 0.99 & 121 \\
\hline & Reverse & GCCATCAAACATACCCTTCTIT & & & \\
\hline \multirow[t]{2}{*}{ TLR9 $^{c}$} & Forward & TTGCTCGCCAAAACACTATG & 99.5 & 0.99 & 150 \\
\hline & Reverse & GGAATCCAGTCCCTCTCCTC & & & \\
\hline \multirow[t]{2}{*}{$Z N F X 1^{b}$} & Forward & ATGCCACTATCGGTGGACAGA & 87.3 & 0.99 & 108 \\
\hline & Reverse & TCAACAGATTATTGCCCTCGG & & & \\
\hline \multirow[t]{2}{*}{ ATPS $^{c}$} & Forward & ACATGGATAAATGGCTIITTGC & 99.6 & 0.98 & 155 \\
\hline & Reverse & TTGAAGAAGTAGTGTGGCTGGA & & & \\
\hline
\end{tabular}

${ }^{a}$ These primers were previously designed and used in Rise et al. [22] but were still quality checked for the present experiment using the reference cDNA as template.

${ }^{\mathrm{b}}$ These primers were previously designed and used in Rise et al. [25] but were still quality checked for the present experiment using the reference cDNA as template.

'These primers were designed based on ESTs or contigs representing probes that were identified as differentially expressed in the microarray experiment.

microarray-identified genes were selected for QPCR because they were previously identified as up-regulated in the spleen of Atlantic cod injected with $\mathrm{pIC}$ and/or in brains of cod with high nodavirus carrier state [22,25]: Deltex3, DHX58 (DExD/H box RNA helicase; aliases
LGP2, RIG-I-c terminal domain containing protein), IL8 (interleukin-8 variant 5), IRF1 (interferon regulatory factor 1), IRF7 (interferon regulatory factor 7), IRF10 (interferon regulatory factor 10), ISG15 (interferon stimulated gene 15, paralogs 1 and 3), RSAD2 (radical S- 
adenosyl methionine domain containing protein 2; alias Viperin), SACS (sacsin; alias spastic ataxia of Charlevoix-Saguenay), SCYA123 [small inducible cytokine 123; this follows the nomenclature for cod $\mathrm{CC}$ chemokines from Borza et al. [58]], STAT1 (signal transducer and activator of transcription 1), TLR3 (Toll-like receptor 3), and ZNFX1 (zinc finger, NFX1-type containing 1). Nine of the 17 microarray-identified genes subjected to QPCR (DHX58, IL-8, IRAK4, IRF1, ISG15, PKR, RSAD2, SCYA123 and ZNFX1) were amongst the 96 overlapping probes (Additional file 1: Table S9) between the list of 279 genes more highly expressed in the pIC 6HPI@ $16^{\circ} \mathrm{C}$ vs. pIC 6HPI@10 $10^{\circ} \mathrm{C}$ comparison and the list of 303 genes more highly expressed in the pIC $24 \mathrm{HPI} @ 10^{\circ} \mathrm{C}$ vs. pIC $24 \mathrm{HPI} @ 16^{\circ} \mathrm{C}$ comparison (Figures 2 and 4). QPCR primers were either chosen from previous publications from our laboratory [22,25] (for IRF1, IRF7, IRF10, SACS, Deltex3, STAT1 and ZNFX1) or designed based on sequences representing informative microarray probes using Primer 3 (http://frodo.wi.mit.edu) (for DHX58, IKB $\alpha$, IL-8, IRAK4, ISG15, PKR, RSAD2, SCYA123, TLR3, TLR9 and ATPS). Every primer set was quality-checked $(\mathrm{QC})$ using reference cDNA templates generated by reverse transcription of the microarray experiment reference RNA. The QPCR primer QC process was carried out as described in Booman et al. [21]. Briefly, a 5 -fold dilution (starting with $10 \mathrm{ng}$ of input RNA) standard curve consisting of 5 points was used to calculate amplification efficiencies [68], and melt-curve analysis was carried out to ensure primer sets amplified a single product and there were no detectable primer dimers. The primer sequences, amplification efficiencies and amplicon sizes are shown in Table 3.

Gene expression was normalized to ATPS [ATP synthase $\mathrm{H}^{+}$transporting, mitochondrial Fo complex, subunit F2; CGP microarray probe identifier (ID) \#36304] mRNA levels. Several steps were taken to ensure that this gene was a suitable normalizer for this QPCR study. Initially, several candidate probes that had overall normalized ratios (i.e. $\log _{2}$ transformed ALEXA 647/ALEXA 555) close to 0 across all 60 microarrays in this study were selected as potential normalizers. For these, the probe IDs for the ones with the lowest standard deviation were searched in all generated gene lists of differentially expressed genes (with $\mathrm{FDR}=1 \%$ ) (Additional files 1: Tables S1-S8), and the ones that were not present in any gene lists were tested with QPCR in a subset of individuals (3 from each condition and time point). ATPS had the lowest threshold cycle $\left(C_{T}\right)$ range (1.2). Lastly, in every multi-plate experiment $C_{T}$ values for ATPS were always checked; if their range was $>1.5$ cycles, the samples more distant from the overall $\mathrm{C}_{\mathrm{T}}$ mean were removed from the study. For any given GOI, no more than 2 individuals had to be removed from the study.
All cDNAs were reverse transcribed from $1 \mu \mathrm{g}$ of DNaseI treated, column purified RNA using the RETROScript kit (Ambion, Austin, TX) following the manufacturer's instructions for the protocol that includes template denaturation. Six individuals from each group were analyzed in triplicate reactions. To QPCR validate the microarray experimentidentified GOI, we used 3 individuals that had been used in the microarray and 3 individuals that were not used for microarray hybridizations. Fish included in the QPCR experiment were also selected based on RNA quality and quantity. PCR amplification and cycling were performed as in Booman et al. [21]. In all plates a linker sample consisting of cDNA made from the reference RNA was included for every target (including the normalizer). Prior to analysis, all linker $C_{\mathrm{T}}$ values were checked; inter-plate variation was never $>0.5$ cycles. All thresholds were set automatically, and relative quantities (RQ) were calculated using actual amplification efficiencies for each primer pair and the linker as a calibrator using the Applied Biosystems (Foster City, CA) 7500 Software Relative Quantification Study Application (v2.0) [69].

Resulting RQs were $\log _{2}$ transformed in Excel (Microsoft Co., Seattle, WA) and analyzed statistically using Prism (v5.0, GraphPad Software Inc, La Jolla. CA). All groups were initially subjected to a KolmogorovSmirnov normality test. For each time point (e.g. 6HPI) a two-way ANOVA with injection (i.e. PIC or PBS) and temperature $\left(10^{\circ} \mathrm{C}\right.$ or $\left.16^{\circ} \mathrm{C}\right)$ as factors was then carried out. When the effects of a given factor were statistically significant $(\mathrm{p}<0.05), \mathrm{t}$-tests were carried out to compare pIC-injected groups to their temperature-matched controls (i.e. PBS injected) at a particular time point, PBS-injected fish held at different temperatures, or pIC-injected fish held at different temperatures. Overall fold-change values were calculated as $2^{\mathrm{A}-\mathrm{B}}$ as suggested by Cui and Churchill [70], where $\mathrm{A}$ is the average $\log _{2}$ transformed RQ from an experimental group (pIC always considered experimental relative to $\mathrm{PBS}$ and $16^{\circ} \mathrm{C}$ always considered experimental relative to $10^{\circ} \mathrm{C}$ ), and $\mathrm{B}$ is the average $\log _{2}$ transformed $\mathrm{RQ}$ from the timeor temperature-matched control.

\section{Additional files}

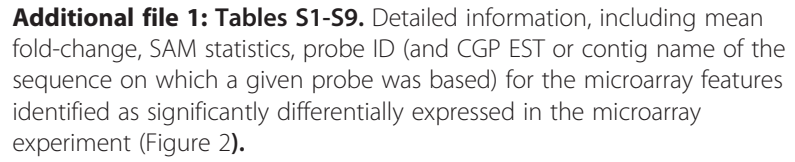

Additional file 1: Tables S1-S9. Detailed information, including mean fold-change, SAM statistics, probe ID (and CGP EST or contig name of the sequence on which a given probe was based) for the microarray features identified as significantly differentially expressed in the microarray experiment (Figure 2).

Additional file 2: Figure S1. Putative type I interferon activation via Toll-like receptors (TLRs) in Atlantic cod.

\section{Competing interests}

The authors declare that they have no competing interests. 


\section{Authors' contributions}

$\mathrm{TSH}$ took a lead role in the design and implementation of the heat exposure/immune stimulation experiments, design and execution of microarray and QPCR experiments, data analysis, data interpretation and the writing of this manuscript. AKG was involved in the design of the heat exposure/immune stimulation experiments, data analysis, data interpretation and took an active part in the writing of the manuscript. MB took an active part in the design of the microarray experiments and microarray data analysis and data interpretation. GWN took an active role in the design and implementation of the heat exposure/immune stimulation experiment and sample preparation for the microarray analysis. MLR was involved in the design of the heat exposure/immune stimulation experiment, design of microarray and QPCR experiment data analysis, data interpretation and the writing of this manuscript. All authors read and approved the final manuscript.

\section{Acknowledgments}

This research was supported in part by Genome Canada, Genome Atlantic, and the Atlantic Canada Opportunities Agency through the Atlantic Cod Genomics and Broodstock Development Project. Funding was also provided by a Canada Research Chair (Tier 2) in marine biotechnology and a Natural Sciences and Engineering Research Council (NSERC) discovery grant to MLR, and the following awards to TSH: the Royal Bank Scholarship in Marine Sciences, the Joe Brown Graduate Research Award; Memorial University of Newfoundland SGS fellowship. The authors would also like to acknowledge the staff of the Dr. Joe Brown Aquatic Research Building (JBARB) for helping with fish husbandry. Lastly, we would like to thank Dr. Stewart Johnson and Dr. Luis Afonso for reading and providing suggestions on earlier versions of this manuscript.

Received: 9 February 2012 Accepted: 22 August 2012

Published: 28 August 2012

\section{References}

1. Myers RA, Hutchings JA, Barrowman NJ: Why do fish stocks collapse? The example of cod in Atlantic Canada. Ecol Appl 1997, 7(1):91-106.

2. Kjesbu OS, Taranger GL, Trippel EA: Gadoid mariculture: development and future challenges. ICES J Mar Sci 2006, 63:187-191.

3. Rose GA: Cod: the ecological history of the North Atlantic fisheries. St. John's: Breakwater Books; 2007.

4. Brown JA, Minkoff G, Puvanendran V: Larviculture of Atlantic cod (Gadus morhua): progress, protocols and problems. Aquaculture 2003, 227:357-372.

5. Roselund G, Halldórsson O: Cod juvenile production: Research and commercial developments. Aquaculture 2007, 268:188-194.

6. Roselund G, Skretting M: Worldwide status and perspectives on gadoid culture. ICES J Mar Sci 2006, 63:194-197.

7. Pérez-Casanova JC, Afonso LOB, Johnson SC, Currie S, Gamperl AK: The stress and metabolic responses of juvenile Atalntic cod Gadus morhua L. to an acute thermal challenge. J Fish Biol 2008, 72:899-916.

8. Gollock MJ, Currie S, Petersen LH, Gamperl AK: Cardiovascular and hematological responses of Atlantic cod (Gadus morhua) to acute temperature increase. J Exp Biol 2006, 209:2961-2970.

9. Pérez-Casanova JC, Rise ML, Dixon B, Afonso LO, Hall JR, Johnson SC, Gamperl AK: The immune and stress response of Atlantic cod to longterm increases in water temperature. Fish Shellfish Immunol 2008, 24:600-609.

10. Alishahi M, Buchmann K: Temperature-dependent protection against Ichthyophthirius multifiliis following immunisation of rainbow trout using live theronts. Dis Aquat Organ 2006, 72:269-273.

11. Raida MK, Buchmann K: Temperature-dependent expression of immunerelevant genes in rainbow trout following Yersinia ruckeri vaccination. Dis Aquat Organ 2007, 77:41-52.

12. Raida MK, Buchmann K: Bath vaccination of rainbow trout (Oncorhynchus mykiss) against Yersinia ruckeri: effects of temperature on protection and gene expression. Vaccine 2008, 26:1050-1062.

13. Bettge $K$, Segner $H$, Burki $R$, Schmidt-Posthaus $H$, Wahli T: Proliferative kidney disease (PKD) of rainbow trout: temperature- and time-related changes of Tetracapsuloides bryosalmonae DNA in the kidney. Parasitol 2009, 136:615-625.
14. Varsamos S, Flik G, Pepin JF, Wendelaar Bonga SE, Breuil G: Husbandry stress during early life stages affects the stress response and health status of juvenile sea bass, Dicentrarchus labrax. Fish Shellfish Immunol 2006, 20:83-96.

15. Cheng $A-C$, Cheng S-A, Chen $Y-Y$, Chen J-C: Effects of temperature change on innate cellular and humoral immune responses of the orangespotted grouper Epinephelus coioides and its susceptibility to Vibrio alginolyticus. Fish Shellfish Immunol 2009, 26:768-722.

16. Eggset G, Mikkelsen H, Killie J-EA: Immunocompetence and duration of immunity against Vibrio salmonicida and Aeromonas salmonicida after vaccination of Atlantic salmon (Salmo salar L.) at low and high temperatures. Fish Shellfish Immunol 1997, 7:247-260.

17. Magnadottir B, Jonsdottir H, Helgason S, Bjornsson B, Jorgensen TO, Pilstrom L: Humoral immune parameters in Atlantic cod (Gadus morhua L.): I. The effects of environmental temperature. Comp Biochem Physiol $B$ Biochem Mol Biol 1999, 122:181-188.

18. Rise ML, Jones SRM, Brown GD, von Schalburg KR, Davidson WS, Koop BF: Microarray analyses identify molecular biomarkers of Atlantic salmon macrophage and hematopoietic kidney responses to Piscirickettsia salmonis infection. Physio/ Genomics 2004, 20:21-35.

19. Milev-Milovanovic I, Majji S, Thodima V, Deng Y, Hanson L, Arnizaut A, Waldbieser G, Chinchar VG: Identification and expression analyses of poly [l:C]-stimulated genes in channel catfish (Ictalurus punctatus). Fish Shellfish Immunol 2009, 26:811-820.

20. Workenhe ST, Hori TS, Rise ML, Kibenge MJ, Kibenge FS: Infectious salmon anaemia virus (ISAV) isolates induce distinct gene expression responses in the Atlantic salmon (Salmo salar) macrophage/dendritic-like cell line TO, assessed using genomic techniques. Mol Immunol 2009, 46(15):2955-2974.

21. Booman $M$, Borza $T$, Feng $C Y$, Hori TS, Higgins $B$, Culf A, Léger D, Chute IC, Belkaid A, Rise M, Gamperl AK, Hubert S, Kimball J, Ouellette RJ, Johnson SC, Bowman S, Rise ML: Development and experimental validation of a $20 \mathrm{~K}$ Atlantic cod (Gadus morhua) oligonucleotide microarray based on a collection of over 150,000 ESTs. Mar Biotechnol (NY) 2011, 13(4):733-750.

22. Rise ML, Hall J, Rise M, Hori T, Gamperl AK, Kimball J, Hubert S, Bowman S, Johnson SC: Functional genomic analysis of the response of Atlantic cod (Gadus morhua) spleen to the viral mimic polyriboinosinic polyribocytidylic acid (pIC). Dev Comp Immunol 2008, 32:916-971.

23. Feng CY, Johnson SC, Hori TS, Rise M, Hall JR, Gamperl AK, Hubert S, Kimball J, Bowman S, Rise ML: Identification and analysis of differentially expressed genes in immune tissues of Atlantic cod stimulated with formalin-killed, atypical Aeromonas salmonicida. Physiol Genomics 2009, 37:149-163.

24. Hori TS, Gamperl AK, Afonso LO, Johnson SC, Hubert S, Kimball J, Bowman S, Rise ML: Heat-shock responsive genes identified and validated in Atlantic cod (Gadus morhua) liver, head kidney and skeletal muscle using genomic techniques. BMC Genomics 2010, 11:72

25. Rise ML, Hall JR, Rise M, Hori TS, Browne MJ, Gamperl AK, Hubert S, Kimball J, Bowman S, Johnson SC: Impact of asymptomatic nodavirus carrier state and intraperitoneal viral mimic injection on brain transcript expression in Atlantic cod (Gadus morhua). Physiol Genomics 2010, 42:266-280.

26. Bowman S, Hubert S, Higgins B, Stone C, Kimball J, Borza T, Bussey JT, Simpson G, Kozera C, Curtis BA, Hall JR, Hori TS, Feng CY, Rise M, Booman M, Gamperl AK, Trippel E, Symonds J, Johnson SC, Rise ML: An integrated approach to gene discovery and marker development in Atlantic cod (Gadus morhua). Mar Biotechnol (NY) 2011, 13(2):242-255.

27. Steinhagen D, Hespe K, Ellmer B, Körting W: Goussia carpelli (Protozoa: Coccidia) infection in stressed and immunosupressed common carp Cyprinus carpio. Dis Aquat Org 1998, 34:199-204.

28. Hamel OS: Immunosupression in progeny of Chinook salmon infected with Renibacterium salmoninarum: re-analysis of a brood stock segregation experiment. Dis Aquat Org 2005, 65:29-41.

29. Verma AK, Pal AK, Manush SM, Das T, Dalvi RS, Chandrachoodan PP, Ravi PM, Apte SK: Persistent sub-lethal chlorine exposure augments temperature induced immunosupression in Cyprinus carpio advanced fingerlings. Fish Shellfish Immunol 2007, 22:547-555.

30. Hansen J, Sato M, Ruedy R, Lo K, Lea DW, Medina-Elizade M: Global temperature change. PNAS 2006, 103(39):14288-14293.

31. Tusher VG, Tibshirani R, Chu G: Significance analysis of microarrays applied to the ionizing radiation response. Proc Natl Acad Sci USA 2001, 98:5116-5121. 
32. Johansson D, Juell J-E, Oppedal F, Stiansen J-E, Ruohonen K: The influence of the pycnocline and cage resistance on current flow, oxygen flow and swimming behaviour of Atlantic salmon (Salmo salar L.) in production cages. Aquaculture 2007, 265:271-287.

33. Oppedal F, Juell J-E, Johansson D: Thermo- and photoregulatorybehaviour influence swimming depth and schooling density of caged Atlantic salmon. Aquaculture 2007, 265:70-81.

34. Wang J-T, Li J-T, Zhang X-F, Sun X-W: Transcriptome analysis reveals the time of the fourth round of genome duplication in common carp (Cyprinus carpio). BMC Genomics 2012, 13:96.

35. Sánchez CC, Weber GM, Gao G, Cleveland BM, Yao J, Rexroad CE III: Generation of a reference transcriptome for evaluating rainbow trout responses to various stressors. BMC Genomics 2011, 12:626.

36. Xiang L-X, He D, Dong W-r, Zheng Y-W, Shao J-z: Deep sequencing-based transcriptome profiling analysis of bacteria-challanged Lateolabrax japonicus reveals insights into the immune-relevant genes in marine fish. BMC Genomics 2010, 11:472.

37. Robertsen B: The interferon system of teleost fish. Fish Shellfish Immunol 2006, 20:172-191.

38. Robertsen B: Expression of interferon and interferon-induced genes in salmonids in response to virus infection, interferon-inducing compounds and vaccination. Fish Shellfish Immunol 2008, 25:351-357.

39. Phelan PE, Mellon MT, Kim CH: Functional characterization of full-length TLR3, IRAK-4, and TRAF6 in zebrafish (Danio rerio). Mol Immunol 2005, 42:1057-1071

40. Galligan CL, Murooka TT, Rahbar R, Baig E, Majchrzak-Kita B, Fish EN: Interferon and viruses, signaling for supremacy. Immunol Res 2006, 35:27-39.

41. Rebl A, Goldammer T, Seyfert H-M: Toll-like receptor signaling in bony fish. Vet Immunol Immunopathol 2010, 134:139-150.

42. Rodriguez MF, Wiens GD, Purcell MK, Palti Y: Characterization of Toll-like receptor 3 gene in rainbow-trout (Oncorhynchus mykiss). Immunogenetics 2005, 57:510-519.

43. Chiou PP, Lin C-H, Bols NC, Chen T: Characterization of virus/doublestranded RNA-dependent induction of the antimicrobial peptide hepcidin in trout macrophages. Dev Comp Immunol 2007, 31:1297-1309.

44. Matsumoto M, Seya T: TLR3: Interferon induction by double-stranded RNA including poly(l:C). Adv Drug Deliv Rev 2008, 60:805-812.

45. Palti $Y$ : Toll-like receptors in bony fish: from genomics to function. Dev Comp Immunol 2011, 35(12):1263-1272.

46. Kaway T, Akira S: Toll-like receptor and RIG-I-like receptor signaling. Ann NY Acad Sci 2008, 1143:1-20

47. Wilkins C, Gale M Jr: Recognition of viruses by cytoplasmic sensors. Curr Opin Immunol 2010, 22:41-47.

48. Gil J, Alcamí J, Esteban M: Activation of NF-kB by the dsRNA-dependent protein kinase, PKR involves the IKB kinase complex. Oncogene 2000, 19:1369-1378.

49. García MA, Meurs EF, Esteban M: The dsRNA protein kinase PKR: virus and cell control. Biochimie 2007, 89:799-811.

50. Kaway T, Akira S: TLR signaling. Cell Death Differ 2006, 13:816-825

51. Li Q, Verma IM: NF-KB regulation in the immune system. Nature Rev Immunol 2002, 2(10):725-734

52. Bonizzi G, Karin M: The two NF-kB activation pathways and their roles in innate and adaptive immunity. Trends Immunol 2004, 25(6):280-288.

53. Tamura $T$, Yanai $H$, Savitsky D, Taniguchi $T$ : The IRF family transcription factors in immunity and oncogenesis. Annu Rev Immunol 2008, 26:535-584.

54. Noppert SJ, Fitzgerald KA, Hertzog PJ: The role of type I interferon's in TLR responses. Immunol Cell Biol 2007, 85:446-457.

55. Bao X, Indukuri H, Liu T, Liao S-H, Tian B, Brasier AR, Garofalo RP, Casola A: IKK $\epsilon$ modulates RSV-induced NF-KB-dependent gene transcription. Virology 2010, 408:224-231.

56. Liu S-Y, Sanchez DJ, Cheng G: New developments on the induction and anti-viral effectors of type I interferon. Curr Opin Immunol 2011, 23:57-64.

57. Furnes $C$, Kileng $\varnothing$, Rinaldo $\mathrm{CH}$, Seppola M, Jensen I, Robertsen B: Atlantic cod (Gadus morhua $\mathrm{L}$ ) possesses three homologues of ISG15 with different expression kinetics and conjugation properties. Dev Comp Immunol 2009, 33:1239-1246.
58. Borza T, Stone C, Rise ML, Bowman S, Johnson SC: Atlantic cod (Gadus morhua) CC chemokines: diversity and expression analysis. Dev Comp Immunol 2010, 34:904-913.

59. Engert JC, Bérubé $P$, Mercier J, Doré $C$, Lepage $P, G$ G B, Bouchard J-P, Mathieu J, Melançon SB, Schalling M, Lander ES, Morgan K, Hudson TJ, Richter A: ARSACS, a spastic ataxia common in northeastern Québec, is caused by mutations in a new gene encoding a 11.5-kb ORF. Nature Genet 2000, 24:120-125.

60. Anderson JF, Siller E, Barral JM: The Sacsin repeating region (SRR): a novel hsp90-related supra-domain associated with neurodegeneration. J Mol Biol 2010, 400:665-674

61. Kultz D: Molecular and evolutionary basis of the cellular stress response. Annu Rev Physiol 2005, 67:225-257.

62. Salminen A, Paimel T, Suuronen T, Kaarniranta $K$ : Innate immunity meets with cellular stress at the IKK complex: regulation of the IKK complex by HSP70 and HSP90. Immunol Lett 2008, 117:9-15.

63. $B \varnothing T H$, Dysvik $B$, Jonassen I: LSimpute: accurate estimation of missing values in microarray data with least squares methods. Nucleic Acids Res 2004, 32:e34.

64. Celton M, Malpertuy A, Lelandais G, de Brevern AG: Comparative analysis of missing value imputation methods to improve clustering and interpretation of microarray experiments. BMC Genomics 2010, 11:15.

65. Schwender $\mathrm{H}$, Krause A, Ickstadt $\mathrm{K}$ : Identifying interesting genes with siggenes. RNews 2006, 6:45-50.

66. Sturn A, Quackenbush J, Trajanoski Z: Genesis: cluster analysis of microarray data. Bioinformatics 2002, 18:207-208.

67. Conesa A, Götz S, Gracía-Gómez JM, Terol J, Talón M, Robles M: Blast2GO: a universal tool for annotation, visualization and analysis in functional genomics research. Bioinformatics 2005, 21(18):3674-3676.

68. Pfaffl MW: A new mathematical model for relative quantification in realtime RT-PCR. Nucleic Acids Res 2001, 29:e45.

69. Livak KJ, Schmittgen TD: Analysis of relative gene expression data using real-time quantitative $P C R$ and the 2(-Delta Delta $C(T)$ ) method. Methods 2001, 2:402-408

70. Cui $X$, Churchill GA: Statistical tests for differential expression in cDNA microarray experiments. Genome Biol 2003, 4:210.

doi:10.1186/1471-2164-13-431

Cite this article as: Hori et al:: A moderate increase in ambient temperature modulates the Atlantic cod (Gadus morhua) spleen transcriptome response to intraperitoneal viral mimic injection. BMC Genomics 2012 13:431.

\section{Submit your next manuscript to BioMed Central and take full advantage of:}

- Convenient online submission

- Thorough peer review

- No space constraints or color figure charges

- Immediate publication on acceptance

- Inclusion in PubMed, CAS, Scopus and Google Scholar

- Research which is freely available for redistribution 